\title{
28 Research Square \\ Comparative Evaluation of Madhuca Longifolia and Jatropha Curcas Extracted Biodiesel.
}

Rajeshwari Chatterjee ( $\nabla$ rajchmimi@gmail.com )

Birla Institute of Technology

Sanat Kumar Mukherjee

Birla Institute of Technology

\section{Biswajit Paul}

IIT (ISM): Indian Institute of Technology

Somnath Chattopadhyaya

IIT (ISM): Indian Institute of Technology

\section{Research Article}

Keywords: Biodiesel, Engine performance \& emissions, FTIR, UV-Vis spectroscopy, NMR

Posted Date: March 9th, 2021

DOI: https://doi.org/10.21203/rs.3.rs-197946/v1

License: (c) (1) This work is licensed under a Creative Commons Attribution 4.0 International License. Read Full License 


\section{Abstract}

In order to fulfil the growing need to replace fossil fuels, investigations exploring the production of biodiesel from agricultural biomass have gained attention. The purpose behind this study is to examine the efficiency of biodiesel extracted from Madhuca longifolia and Jatropha curcas by means of pretreatment followed by two step acid-base homogeneous catalyst method. The Madhuca and Jatropha biodiesels were blended with diesel at different percentages. Fourier Transform Infrared Spectroscopy (FTIR) showed a strong presence of fatty acid profile, and triglyceride ester linkage at $1744 \mathrm{~cm}^{-1}$. UV-Vis spectra confirmed the presence of conjugated dienes in the extracted biodiesels. UV absorbance at 320 $\mathrm{nm}$ decreases linearly with blend percentage. ${ }^{1} \mathrm{HNMR}$ and ${ }^{13} \mathrm{C}$ NMR confirmed the presence of methyl ester moiety at $3.6 \mathrm{ppm}$ and methoxy carbon at $51.2 \mathrm{ppm}$ in biodiesel distinguishing it from diesel. Raman spectra exhibited $\mathrm{C}=0$ stretching at $1725 \mathrm{~cm}^{-1}$ indicating conversion of Madhuca and Jatropha oil into biodiesel. The engine performance and emission tests of these biodiesels were evaluated. In the engine performance tests, the variations of brake specific fuel consumption (BSFC), exhaust gas temperature (EGT), and brake thermal efficiency (BTE) versus brake power were studied. The emission tests of different blends were done in terms of carbon mono-oxide, nitrous oxide, and unburnt hydrocarbon (UHC). The Jatropha biodiesel exhibited less mean BSFC, EGT and emitted less CO and UHC than Madhuca biodiesel. The average decrease in BTE was more in Jatropha biodiesel than Madhuca biodiesel.

\section{Introduction}

Biodiesel as an alternative fuel is non-toxic, renewable, biodegradable, and carbon-neutral fuel (Chatterjee et al.2015). Earlier research indicates that biodiesels emit lesser $\mathrm{CO}$, and particulate matter but higher NO as compared to diesel (Joshi and Pegg 2007). Kannan (2019) revealed that oxidation catalysts decrease oxidation temperature, which reduces NOx emission. Addition of nano additives enhances thermal efficiency and lowers fuel consumption (Ganesan et al. 2020). In the combustion process biodiesel exhibits no efficiency loss, despite its heat of combustion being slightly lower than that of diesel (Raheman and Ghadge 2007).

During the storage process biodiesel undergoes oxidative degradation because of the presence of reactive unsaturated fatty acid esters mainly oleate, and linoleate (Pantoja et al. 2013). This degradation leads to alteration in peroxide value, decomposing hydroperoxides to ketones, and oligomers (Bondioli et al. 2003). The degradation further leads to poor performance like seal swelling of the elastomer, and dilution of engine (Karavalakis and Stournas 2010). Fourier transform infrared spectroscopy (FTIR) is mainly used to observe oxidative degradation of biodiesel (Bacha et al. 2015). Its absorption at around $1745 \mathrm{~cm}^{-1}$ is due to the existence of ester carbonyl group (Zhou et al. 2017). Faragun et al. (2019) observed high linearity correlation between concentration and FTIR absorption ( $R^{2}$ above 0.998 ). Shimamoto and Tubino (2016) explored the presence of conjugated dienes in oxidized biodiesel and 
found positive correlation between peroxide value and the UV absorbance and having two intense absorption bands along the 230-260 nm wavelengths (Shimamoto and Tubino 2016).

Several authors studied Raman spectra for the estimation of transesterification reaction, and ester composition of biodiesel. Several researchers also studied the intensity and position of $\mathrm{C}=\mathrm{O}$ of carbonyl group. Authors observed high correlation $\left(R^{2}\right.$ above 0.99$)$ between biodiesel concentration and Raman spectra (Ghesti et al. 2007).

Nuclear Magnetic Resonance (NMR) technique is applied to determine the chemical structure of compounds associated in biodiesel synthesis (Ghesti et al. 2007).

It is also used for quantifying biodiesel in diesel-biodiesel blends, and changes in the fatty acid content (Shimamoto and Tubino 2016). Knothe (2001) reported olefin protons (5.3-5.4 ppm), methyl ester peaks (3.6-3.7 ppm), and methyl protons of the hydrocarbon moieties in biodiesel in establishing biodieseldiesel blends.

Monteiro et al. (2009) analysed the effectiveness of ${ }^{1} \mathrm{H}$ NMR in influencing the blend of methyl biodiesel in diesel fuels, using castor oils, soybean biodiesel and three diesel fuels.

Anderson (2012) exhibited NMR spectra for studying formation of triacylglycerol, and FAME in biodiesel production. Satyarthi et al. (2009) utilized NMR spectroscopy to establish free fatty acid value (FFA). Authors estimated FFA content using $\mathrm{R}-\mathrm{CH}_{2}$ of FFA and ester.

The shifting of paraffin hydrocarbon and $\mathrm{O}_{2}$ content reduces the effect of biodiesel (Schmid and Gerpen 1996). Tat et al. (2004) found cetane number (CN) and NOx emissions are inversely correlated. Several researchers revealed biodiesels emit less NOx and have higher degree of saturation (Knothe et al. 2006). Pinzi et al. (2013) pointed NOx, HC, and CO emissions increase with an increased chain length of unsaturated FAME. NOx emission increases with decreasing chain length of fully saturated fatty acids.

The present work uses for the first-time treatment of ortho phosphoric acid $\left(\mathrm{H}_{3} \mathrm{PO}_{4}\right)$ and toluene $\left(\mathrm{C}_{7} \mathrm{H}_{8}\right)$, to produce biodiesel followed by two step homogeneous acid-base catalyst method. The efficiency of this method is evaluated by using two variants of biodiesels: Madhuca longifolia and Jatropha curcas. This treatment drastically reduces the FFA value which in turn increases the performance of the biodiesels.

\section{Production}

The novelty in the production method is pre-treatment of oil by addition of $\mathrm{C}_{7} \mathrm{H}_{8}$, and $\mathrm{H}_{3} \mathrm{PO}_{4}$, which removes impurities. $\mathrm{C}_{7} \mathrm{H}_{8}$ is also added both in transesterification and esterification steps, which removes impurities, and results in the addition of less catalyst. The acid-base two-step process enhances the yield and reduces the FFA value. The reduction of FFA is the indicator of efficient fuel exhibiting high performance tests. Figure 1 represents the production of biodiesel from Madhuca and Jatropha. 
FFA of pure Madhuca oil was $19 \%$, which was reduced to $2 \%$ by pre-treatment with $\mathrm{C}_{7} \mathrm{H}_{8}$, and $\mathrm{H}_{3} \mathrm{PO}_{4}$, subsequently reduced to $0.91 \%$ by transesterification step and $0.3 \%$ by three step production method. The yield was $97.6 \%$. Similarly, in Jatropha oil FFA was reduced from $20-1.45 \%$ in the first step of pretreatment, which was further reduced to $0.8 \%$ by transesterification by acid $\mathrm{H}_{2} \mathrm{SO}_{4}$ catalyst and finally to $0.2 \%$ by base catalyst. The yield was also $98 \%$.

\subsection{Experiment details}

Both Madhuca and Jatropha oils were obtained commercially from Uttar Pradesh, India. NMR solvent $\mathrm{CDCl}_{3}(99 \%)$ was obtained from Sigma Aldrich, $\mathrm{n}$-Heptane (99\%), $\mathrm{NaOH}$ pellets from Thermo Fisher, $\mathrm{H}_{3} \mathrm{PO}_{4}$, and $\mathrm{H}_{2} \mathrm{SO}_{4}$ from Rankem, $\mathrm{CH}_{3} \mathrm{OH}$ from Fisher Scientific.

The produced Jatropha curcas (JB) and Madhuca longifolia (MB) biodiesels were blended with diesel at varying proportions ranging within $0-95 \%$ characterization.

The characterization of all blended samples of JB and MB was performed by FTIR (Make-Shimadzu Corp, spectrometer, wave number ranging from $\left.7500-350 \mathrm{~cm}^{-1}\right)$. The absorption spectra of all samples were obtained by using UV-vis spectrophotometer (Make- Perkin Elmer Lambda 25 UV/Vis spectrometer) in the wavelength range of $190 \mathrm{~nm}-1100 \mathrm{~nm}$ with a $10 \mathrm{~mm}$ quartz cuvette at room temperature. All the blended JB and MB samples were diluted with $\mathrm{n}$ - Heptane to bring the absorbance to the measurable range of the spectrophotometer. Again, each spectrum was recorded 3 times. $9.9 \mathrm{ml}$ of $\mathrm{n}$ - Heptane was mixed with $0.1 \mathrm{ml}$ of the sample to prepare the final sample. The dilution of JB and MB with aromatic compounds i.e., diesel resulted in decrease in absorbance wavelength. NMR analysis was conducted by using JEOL JNM spectrometer, at $298 \mathrm{~K}$. NMR spectra for all samples were obtained using $1 \mathrm{ml} \mathrm{CDCl}$ as solvent, mixed with $0.1 \mathrm{ml}$ of each sample. Raman Spectra was performed by using Renishaw InVia Raman Spectrometer. The $785 \mathrm{~nm}$ laser line was employed, and grating has $1200 \mathrm{l} / \mathrm{mm}$.

The engine was made to run on pure diesel, and its various blends of $\mathrm{MB}$ and JB. The performance was studied at four different loads (\%) at constant $1500 \mathrm{rpm}$. AVL Di-Gas analyser was used to measure the exhaust gases i.e., carbon monoxide (CO), Oxides of nitrogen

$\left(\mathrm{NO}_{\mathrm{X}}\right)$, and unburnt hydrocarbon (UHC) of the engine. The inlet manifold of the analyser was connected to the exhaust valve of the engine to measure the emission gases. Table 1 depicts engine specifications. 
Table 1

Engine specifications

\begin{tabular}{|llll|}
\hline S. No. & Item & Units & Specifications \\
\hline 1. & Manufacturer & & Kirloskar Oil Engines Ltd \\
\hline 2. & Engine Capacity & $\mathrm{hp}$ & 10 \\
\hline 3. & Cylinder & 1 \\
\hline 4. & Stroke & 4 \\
\hline 5. & Compression Ratio & & $17.5: 1$ \\
\hline 6. & Bore & $\mathrm{mm}$ & 102 \\
\hline 7. & Stroke & $\mathrm{mm}$ & 116 \\
\hline 8. & Ignition & & Compression \\
\hline 9. & Max. Power @ rpm & $\mathrm{kW}$ & $6.7 \mathrm{~kW} @ 3000 \mathrm{rpm}$ \\
\hline 10. & Cooling System & & Water Cooled \\
\hline 11. & No. of Valves / Cylinder & & 1 \\
\hline
\end{tabular}

\section{Result And Discussion}

\subsection{Characterization}

\subsubsection{Physical Characterization}

All physio-chemical properties namely viscosity, calorific value, density, flash point, and fire point of different blends of Jatropha and Madhuca biodiesels are provide in the supplementary sheet. Figure 2 shows the variation of kinematic viscosity of biodiesel blends as a function of blend percentage. It is observed the kinematic viscosity increases linearly with the blending ratios of biodiesel both in JB and MB. This increase in kinematic viscosity arises due to lower density of diesel than biodiesel. Both JB and $M B$ have showed similar linear behaviour. However, their slope and starting point is relatively different from other literature (Acharya et al. 2017, 2019; Jain and Sharma 2011; Raheman and Ghadge 2007; Rashed et al.2016; Shahabuddin et al. 2012). It may be stated that initial diesel viscosity would decide the rate of which other blends changes. The lower the viscosity greater is the linearity. Viscosity increases with increase in carbon chain length in biodiesel (Shahabuddin et al. 2012). The variation observed by Shahabuddin et al. (2012) is non-linear and is not similar with other literature studies (Fig. 2).

The calorific value of various biodiesel blends decreases linearly as a function of blending percentage (Fig. 3). The increase in biodiesel percentage in biodiesel-diesel blend reduces the calorific value due to 
lower calorific value of biodiesel than diesel. Both JB and MB have showed similar behaviour. However, their slope is different from other literature.

\subsubsection{Raman Spectra}

Figure 4a-b represents Raman spectra of all blending samples of JB and MB with diesel and pure diesel. All blends of JB) and MB show peak at around $2935 \mathrm{~cm}^{-1}$, which corresponds to $v_{\mathrm{CH} 2}$. The peak at around $1739 \mathrm{~cm}^{-1}$ represents $v_{\mathrm{C}=0}$ band. The spectra band at 865 corresponds to $\mathbb{\mathrm { R }}_{\mathrm{R}-\mathrm{C}=\mathrm{O}}$ and $\mathbb{\mathrm { R }}_{\mathrm{R}-\mathrm{C}-\mathrm{O}}$. The band at around 378 represents $\square_{\mathrm{co}-\mathrm{o}-\mathrm{c}}$. Both bands at 865 and 378 are due to the formation of ester (Ghesti et al. 2006). The different blends of JB and MB blends show peak at about $1725 \mathrm{~cm}^{-1}$ and 1740 $\mathrm{cm}^{-1}$. The spectra at $1725 \mathrm{~cm}^{-1}$ and $1740 \mathrm{~cm}^{-1}$ represents $C=O$ and $C=C$ respectively. In almost all blends of JB and MB spectrum between $800-900 \mathrm{~cm}^{-1}$ is present. It is due to $C_{1}-C_{2}, C-O$ stretching and $\mathrm{CH}_{3}$ rocking (Miranda et al. 2014).

The peak around $1030-1090 \mathrm{~cm}^{-1}$ is due to weak C-C stretching present in all biodiesel blends. The peak scissoring around $1240 \mathrm{~cm}^{-1}$ and $1250 \mathrm{~cm}^{-1}$, is seen in higher biodiesel blends and is due to $=\mathrm{C}-\mathrm{H}$ bending. Again, $\mathrm{CH}_{2}$ bending is seen twisting between 1295 and $1300 \mathrm{~cm}^{-1}$ and also flapping between $1355 \mathrm{~cm}^{-1}$ and $1385 \mathrm{~cm}^{-1}$ in all JB and MB blends. The peaks around $1480-1500 \mathrm{~cm}^{-1}$ indicates bending of $\mathrm{CH}_{2}$ and $\mathrm{CH}_{3}$.Again peak at $1650-1690 \mathrm{~cm}^{-1}$ is due to $\mathrm{C}=\mathrm{C}$ stretching. $\mathrm{C}=\mathrm{O}$ stretching is also seen between $1740-1750 \mathrm{~cm}^{-1}$ confirming biodiesel production. The vibration of $\mathrm{C}-\mathrm{H}$ stretching is present at nearly $2800-3000 \mathrm{~cm}^{-1}$. The peak at $3000-3050$ is due to the stretching of olefinic $=\mathrm{C}-\mathrm{H}$ as per the literature (Miranda et al. 2014).

\subsubsection{Fourier transform infrared spectroscopy}

The FTIR spectra of pure diesel, JB and MB and their blends with diesel are depicted in Fig. 5a and 5b. The spectral pattern of diesel, all blends of JB with diesel (J5 to J100) and all blending samples of MB with diesel (M5 to M100) lies between the spectral ranges from $500 \mathrm{~cm}^{-1}$ to $4000 \mathrm{~cm}^{-1}$. FTIR spectral region from $1688-1810 \mathrm{~cm}^{-1}$ is $\mathrm{C}=0$, which determines methyl in biodiesel-diesel blends. The spectra area from $1700-1800 \mathrm{~cm}^{-1}$ is owing to stretching of $C=0$. This peak is present in fatty acid methyl ester (FAME), J100, M100 and in all blends of JB and MB, which is ester. The absorption from 1300-1470 $\mathrm{cm}^{-}$

${ }^{1}$ presents in all blends of JB and MB relates to bending of $-\mathrm{CH}_{3}$ asymmetric stretching. ${ }^{14} \mathrm{Fig} .5 \mathrm{a}-\mathrm{b}$ depicts that $\mathrm{OH}$ spectra is absent in the absorption range from $3600-3500 \mathrm{~cm}^{-1}$ in diesel and in all blends of JB and MB, indicating the absence of residual alcohol or un-reacted methanol (Shah 2013). A peak present at all blends of $M B$ and $J B$ at $1743.65 \mathrm{~cm}^{-1}$ shows the presence of strong ester carbonyl bond $(C=0)$ signifying FAME or biodiesel. This is one of the major differences of biodiesel from diesel, where peak in the range of $1740-1755 \mathrm{~cm}^{-1}$ is missing (Fig. 5a-b). Infrared spectrum from all samples of both $\mathrm{JB}$ and $\mathrm{MB}$ at $1745 \mathrm{~cm}^{-1}$ depicts the triglyceride ester linkage. The aromatic hydrocarbon is present in the spectrum range from $722 \mathrm{~cm}^{-1}$ to $1095 \mathrm{~cm}^{-1}$, whereas spectrum ranging from 1175 to $1245 \mathrm{~cm}^{-1}$ indicates C-O absorption (Chatterjee et al. 2015); absorption ranging from 1362-1373 cm-1 designates 
the $\mathrm{CH}_{3}$ group whereas the peak at $1458 \mathrm{~cm}^{-1}$ is the bending absorption of $\mathrm{CH}_{2}$. Each sample spectrum ranging from $2800 \mathrm{~cm}^{-1}$ to $3000 \mathrm{~cm}^{-1}$ corresponds to $\mathrm{C}-\mathrm{H}$. The IR spectra of all blends of JB (J5-J100) and MB (M5-M100) show strong ester linkage at $1752.31 \mathrm{~cm}^{-1}$. IR spectra of blends of JB (J10, J20, J40, J50, J85, J90, J95, J100) and blends of MB (M5, M15, M20, M50, M85, M90, M100) show strong ester peak (C-O vibrations) around $1173-1230 \mathrm{~cm}^{-1}$. No interference was detected in the $1750 \mathrm{~cm}^{-1}$ region, but diesel signals interfered in the region of $1170-1200 \mathrm{~cm}^{-1}$.

The peaks at $2935-2931 \mathrm{~cm}^{-1}$ in JB blends (J5-J20, J40, J50, J80-J100), MB blends (M5-M20, M40, $\mathrm{M} 50, \mathrm{M} 80-\mathrm{M} 100)$ and in diesel is due to $-\mathrm{C}-\mathrm{H}_{2}$ stretching; also, spectra ranging from $3100 \mathrm{~cm}^{-1}$ until $2700 \mathrm{~cm}^{-1}$ is absorption for $\mathrm{C}-\mathrm{H}$ (Bardley 2007). The spectra of all JB and MB blends exhibited $-\mathrm{C}-\mathrm{H}_{2}$ symmetric stretching at $2854 \mathrm{~cm}^{-1}$. The absence of peak in spectra ranging from $3110 \mathrm{~cm}^{-1}-3500$ $\mathrm{cm}^{-1}$, in JB and MB indicates low water content. The absorption ranging from $964-1018 \mathrm{~cm}^{-1}$ of all blends of $\mathrm{JB}$ and $\mathrm{MB}$ is due to $-\mathrm{C}=\mathrm{C}$ - bending. The characteristics absorption spectra at 1242-1246 $\mathrm{cm}^{-1}$ (J50-J100, M40-M80, M90-M100); $1195 \mathrm{~cm}^{-1}$ (J40, J60-J85,100); and $1167 \mathrm{~cm}^{-1}$ (J5-J100, M5$\mathrm{M} 100$ ) is due to $-\mathrm{C}-\mathrm{O}-\mathrm{C}$ - stretching as per previous literature (Berman et al. 2016).

The calibration model was plotted using Magic Plot Student and Origin 8.2 software. The linearity was determined at selected peak at $1745 \mathrm{~cm}^{-1}$ using base points from $1800 \mathrm{~cm}^{-1}$ to $1600 \mathrm{~cm}^{-1}$. The peak height was correlated against half width half maximum (HMWM). The linearity over the selected peak at $1745 \mathrm{~cm}^{-1}$ showed high co-efficient $R^{2}=0.9243$ in case of JB and its blends (Fig. 6a) and $R^{2}=0.9184$ in case of MB and its respective blends (Fig. 6b).

\subsubsection{UV spectroscopic analysis}

Figure 7a and 7b show the UV-vis spectra of MB and JB biodiesels. UV spectroscopy indicates the occurrence of conjugated dienes in pure diesel, JB and MB and their blends (J5 to J100 and M5 to M100) with diesel. In the present study all JB and MB blends with diesel were diluted with $n$-heptane to bring the absorbance to the measurable range of spectrophotometer. The dilution of JB and MB with aromatic compounds i.e., diesel resulted in decrease in absorbance wavelength. The mono and fully saturated FAAE in the UV region are not absorbed with linoleic acid methyl ester and with linolenic methyl ester, but poly-unsaturated samples are absorbed strongly having a unique characteristic spectrum (Chuck et al. 2010).

In blended percentages of JB and MB with diesel, no change was indicated in the characteristic shape of absorbance curve except in the magnitude of absorbance.

The double bonds unsaturated FAME would isomerize to form the more stable conjugated $\mathrm{C}=\mathrm{C}-\mathrm{C}=\mathrm{C}$ or $\mathrm{C}=\mathrm{C}-\mathrm{C}=\mathrm{O}$ in the degradation of blended biodiesel (Vega-Lizama et al.2015). The oxidative products possessing conjugated double bonds absorb energy both in visible and ultra-violet regions. 
The decreasing absorption trend was observed in $\mathrm{MB}$ blends from $80 \mathrm{M}$ to $100 \mathrm{M}$ in the spectral band of 245-275 nm, where M100 has the lowest coefficient (Fig. 7b). The linearity of absorbance declines with the augmentation in biodiesel blending with biodiesel and diesel due to the decreased concentration of aromatic compounds (Fig. 8a-b). The linear line fitted for absorbance versus the different blended percentages of JB and MB biodiesels at $320 \mathrm{~nm}$ showed a high coefficient of determination $\left(R^{2}=0.906\right.$ and 0.963).

\subsubsection{Nuclear Magnetic Resonance}

${ }^{1} \mathrm{HNMR}$ spectra of blending samples of JB (J5 to J100) with diesel and MB (M5 to M100) with diesel showed a characteristic singlet peak of methyl ester moiety at $3.6 \mathrm{ppm}$ (Fig. 9a-b). The existence of the peaks has been observed in the spectrum of within 3.59-3.63 ppm in all biodiesel blends. This confirms the production of biodiesel. The decrease trend or absence of the peak at $4.00 \mathrm{ppm}$ indicates the production of biodiesel i.e., assigned to hydrogen of glycerol moiety of Jatropha and Madhuca oil.

The presence of triplets in the blends of JB (J10, J15, J40, J80, J90) and MB (M5-M20, M40, M60, M80M100) at $0.8 \mathrm{ppm}$ is methyl hydrogen which makes them distinct from diesel.

In J100 and M100 spectra, peaks situated at 2.1, 2.78 and 5.33 ppm are allylic, bis-allylic and olefinic hydrogen, respectively. The NMR spectra of $\mathrm{J} 100$ and M100 showed peak at 1.3, $1.57 \mathrm{ppm}$ and $1.57 \mathrm{ppm}$ are methylene of carbon chain and from beta- carbonyl methylene. The peak at $2.27 \mathrm{ppm}$ confirms the presence of carbonyl group of the ester moiety (Monteiro et al. 2015).

NMR spectrum of diesel showed a group of peaks at 0.8-2.8 ppm which is from aliphatic hydrogen and quite a few peaks at 6.79-7.25 range from aromatic hydrogen (Fig. 10a-b). Table 2 depicts the functional group of the $\mathrm{JB}$ and $\mathrm{MB}$ samples peaks in ppm of ${ }^{1} \mathrm{H}$ NMR. 
Table 2

Functional group and its respective ppm of the sample's peaks in ${ }^{1} \mathrm{H}$ NMR.

\begin{tabular}{|lll|}
\hline Sample's where peaks are present & Functional Group & ppm \\
\hline $\mathrm{J} 10, \mathrm{J15}, \mathrm{J40}, \mathrm{J} 80, \mathrm{~J} 90, \mathrm{M} 5-\mathrm{M} 20, \mathrm{M} 40, \mathrm{M} 60, \mathrm{M} 80-\mathrm{M} 100$, Diesel & $-\mathrm{CH}_{2}-\mathrm{CH}_{3}$ & $0.84-0.90$ \\
\hline $\mathrm{J} 5-\mathrm{J} 100, \mathrm{M} 5-\mathrm{M} 100$ & $-\mathrm{CH}_{2}-\mathrm{CH}_{3}$ & $0.92-1.29$ \\
\hline $\mathrm{J} 15, \mathrm{~J} 20, \mathrm{~J} 90, \mathrm{~J} 95, \mathrm{J100}, \mathrm{M} 15, \mathrm{M} 100$ & $-\mathrm{OCO}^{-} \mathrm{CH}_{2}-\mathrm{CH}_{2}$ & $1.54-1.71$ \\
\hline $\mathrm{J} 5-\mathrm{J} 100, \mathrm{M} 5-\mathrm{M} 100$ & $-\mathrm{CH}_{2}-\mathrm{C}=\mathrm{C}-$ & $1.96-2.15$ \\
\hline $\mathrm{J} 100$ & $-\mathrm{OCO}^{-} \mathrm{CH}_{2}$ & 2.27 \\
\hline $\mathrm{J} 5-\mathrm{J} 100, \mathrm{M} 15, \mathrm{M} 20, \mathrm{M} 40, \mathrm{M} 50$ & $-\mathrm{OCO}-\mathrm{CH}_{2}$ & $2.10-2.52$ \\
\hline $\mathrm{J} 5-\mathrm{J} 90, \mathrm{~J} 100$ & $\mathrm{C}=\mathrm{C}-\mathrm{CH}_{2}-\mathrm{C}=\mathrm{C}$ & $2.75-2.83$ \\
\hline $\mathrm{J} 5-\mathrm{J} 100, \mathrm{M} 5-\mathrm{M} 100$ & $-\mathrm{COOCH}$ & $3.59-3.68$ \\
\hline M5-M100, J5-J100 & $-\mathrm{CH}=\mathrm{CH}_{3}$ & $5.24-5.42$ \\
\hline
\end{tabular}

${ }^{13} \mathrm{C}$ NMR spectrum shows the presence of methoxy carbon at $51.20 \mathrm{ppm}$ in JB and MB and its blends, confirming the conversion of Jatropha and Madhuca oils to methyl ester. The characteristics peak of carbonyl carbon at 173.92 is present in all blends of MB and JB. The peaks around $129.8 \mathrm{ppm}$ present in all mixtures of JB and MB with diesel indicates olefinic carbon (unsaturation in methyl esters). The signal at 14.21 present in all blends is due to methyl carbon and peaks around $33-21 \mathrm{ppm}$ are due to methylene carbon of long chain FAME. All these peaks are assigned as per literature (Tariq et al. 2011). Table 3 depicts the functional group of the JB and MB samples peaks in ppm of ${ }^{13} \mathrm{C}$ NMR. The different blends of $\mathrm{JB}$ and $\mathrm{MB}{ }^{1} \mathrm{H}$ NMR and ${ }^{13} \mathrm{C}$ NMR graphs are provided in supplementary sheet.

Table 3

Functional group and its respective ppm of the sample's peaks in ${ }^{13} \mathrm{C}$ NMR.

\begin{tabular}{|lll|}
\hline Sample's where peaks are present & Functional Group & ppm \\
\hline J5-J100, M5-M100 & methoxy carbon & 51.2 \\
\hline J5-J100, M5-M100 & methylene and methyl carbons & $33.98-14.21$ \\
\hline J5-J100, M5-M100 & olefinic carbon & $129.8-128.03$ \\
\hline J15-J100, M5-M100 & carbonyl carbon & 173.92 \\
\hline
\end{tabular}

\subsection{Engine Performance and Emission Characteristics 3.2.1. Brake specific fuel consumption}


Figure 11a-b depicts the variation in BSFC with different loads (\%) for Jatropha (JB) and Madhuca (MB) biodiesels. The BSFC of diesel and all JB and MB blends have a decreasing trend with increasing load and an increasing trend with the increase in the proportion of JB and $\mathrm{MB}$ in the fuel blends with diesel. The reason behind is percent increase in fuel required to operate engines, is less, as compared to percent increase in brake power, since less proportion of heat is lost at higher loads. Biodiesels having poor spray characteristics, and thus having differences in mixture formation, owing to their higher kinematic viscosity and density, as compared to diesel fuel. Thus, more biodiesel is required to produce the same torque.

The mean BSFC for the JB was higher than that of diesel by 1.65\% (J5), 2.51\% (J10), 3.45\% (J15), 3.50\% (J20), 17.5\% (J40), 20.4\% (J60), 29.01\% (J80), and 36.5\% (J100). Similarly, in MB mean BSFC with respect to diesel was higher by $4.62 \%$ (M5), 7.01\% (M10), 8.86\% (M15), 8.66\% (M20), 13.5\% (M40), 21.5\% (M60),32.22(M80) and 37.2\% (M100). Thus, the mean BSFC of JB is better than MB.

Higher biodiesel densities result in higher BSFC values. The densities of M100 and $\mathrm{J} 100$ was $3.5 \%$ and $4.1 \%$ respectively higher than diesel, indicating that consumption of the same fuel on volume basis resulted in $3.5 \%$ and $4.1 \%$ higher BSFC in case of $\mathrm{M} 100$ and $\mathrm{J} 100$, respectively. Blends of biodiesel with higher densities at same pressure injection create greater mass injection for the same volume (Raheman and Ghadge 2007).

\subsubsection{Brake Thermal Efficiency}

Figure 12a-b depicts the change in BTE as a function of load variation for compression ratio 17.5:1 for JB and MB. BTE decreases with increasing concentration of JB and MB blends. The increasing trend of efficiency was also seen for diesel as well as for JB and MB. The maximum BTE for JB and MB were $24.12 \%$ for $\mathrm{J} 5$ and $24.01 \%$ for M5 at full load (100\%) as against $24.2 \%$ in diesel. The thermal efficiency for JB and MB blends were less than that of diesel. It is due to slow-burning rate, lower calorific values, poor volatility, and high viscosity. It was also observed that variations in BTE was less for various JB and MB blends at full load (100\%) conditions than that of part load. It is because at higher load more amount of fuel gets burnt due to the increase in temperature (Dutta and Mandal 2018).

The average decrease in BTE for JB blends was 0.9\% (J5), 1.59\% (J10), 3.2\% (J15), 16.8\% (J20), 14.7\% (J40), 16.8\% (J60), 18.9\% (J80), and 23.5\% (J100) than diesel. Similar trend was also observed in MB.

\subsubsection{Exhaust gas temperature}

Figure 13a-b indicates EGT variations with load (\%) for different JB, MB blends and diesel. EGT increases with an increase in load because more amount of fuel is needed to generate extra power to resist extra loading. The average increase in EGT for JB blends was 1.07\% (J5), 1.29\% (J10), 4.39\% (J15), 6.42\% (J20), 10.25\% (J40), 14.93\% (J60), 16.17\% (J80), and 19.17\% (J100) higher than diesel. Similarly, mean increase trend was also obtained in MB as 4.63\% (M5), 5.82\% (M10), 7.01\% (M15), 13.55\% (M20), 15.33\% (M40), 15.9\% (M60), 20.09\% (M80), and 27.46\% (M100). Thus, JB exhibits better EGT than MB. The higher concentration of biodiesel exhibits higher EGT due to more heat losses, and a higher CN. 
The higher $\mathrm{CN}$ of the fuel displays lower ignition delay, thus resulting in a shorter premixed combustion period. At higher load (\%), both J100 and J20 and diesel have comparable EGT. The mean difference between diesel and J20 was not much at $100 \%$ load, probably due to more injection of fuel, resulting in more heat losses.

\subsubsection{Carbon Monoxide}

$\mathrm{CO}$ emissions variation with respect to load for diesel, different blends of JB, MB is illustrated in Fig. 14ab.CO decreases with an increase in JB and MB blends because higher biodiesel blends result in complete oxidation as against diesel. At the time of biodiesel combustion, the produced $\mathrm{CO}$ is perhaps converted to $\mathrm{CO}_{2}$ by taking a molecule of $\mathrm{O}_{2}$ from the biodiesel chain. $\mathrm{CO}$ initially decreases with full load initially and then again increases swiftly up to full load both in case of JB and MB along with their respective blends. At first in the low load condition, the cylinder temperature was low and later it increased swiftly with increase in load. It is because of more injection of fuel inside the cylinder. The cylinder was initially low in the low load condition, and subsequently, with increase in load, it increased swiftly, on account of the availability of more injection of fuel inside the cylinder. At a higher temperature, engine performance improves with comparative enhancement in the burning rate of fuel thus resulting in decreased $\mathrm{CO}$.

Again, additional loading, requires more fuel leading to formation of smoke. It might prevent oxidation of $\mathrm{CO}$ into $\mathrm{CO}_{2}$ resulting in increment of $\mathrm{CO}$ emission. The average decrease in $\mathrm{CO}$ for $\mathrm{JB}$ blends were $6.66 \%$ (J5), 15\% (J10), 16.6\% (J15), 18.3\% (J20), 21.6\% (J40), 41.6\% (J60), $51.6 \%$ (J80), 68.3\% (J100) lower than diesel. Similarly, mean decrease trend was also obtained in MB as 10\% (M5), 11.6\% (M10), 16.6\% (M15), 16.6\% (M20), 26.66\% (M40), 26.66\% (M60), 45\% (M80), and 58.33\% (M100). Thus, C0 emissions was less in JB than MB.

\subsubsection{Nitrous oxide $\left(\mathrm{NO}_{\mathrm{x}}\right)$}

Emission of NOx increases with increase in respective blends of JB and MB with diesel (Fig. 15a-b). It is due to increased $E G T$, and presence of $\mathrm{O}_{2}$ content in JB and MB resulting in NOx formation. At a lower temperature, atmospheric nitrogen exists as a stable diatomic molecule, with a small amount of $\mathrm{NO}_{X}$, but at a higher temperature, in the combustion chamber of an engine, some diatomic nitrogen breaks down to mono atomic nitrogen, which is reactive. NOx varies linearly with increase in percentage of load. At a higher load percentage, the fuel-air ratio increases, consequently increasing the average gas temperature in the combustion chamber, thus resulting in NOx formation on account of its susceptibility to temperature increment.

The average increase in NOx of JB blends were 4.47\% (J5), 12.6\% (J10), 8.96\% (J15), 0\% (J20), 14.17\% (J40), 17.1\% (J60), $20.14 \%$ (J80), 20.14\% (J100) lower than diesel. A similar increase in trend was also observed in MB blends. Biodiesel contains more oxygen content than diesel, which leads to higher emissions of NOx because of complete high combustion temperature (Cheng et al.2009; Devan et al. 2009). Kalam et al. (2011) indicated higher fuel viscosity, which is due to bigger droplet size injection which enhances higher NOx emissions. 


\subsubsection{Unburnt Hydrocarbon (UHC)}

Figure 16a-b depicts a decrease of UHC emissions with increasing blends of JB and MB. It is due to higher $\mathrm{CN}$ of biodiesels which results in delayed combustion. Fuel atomization enhances ignition and mixing resulting in efficient combustion. Fuel properties affect mixing, and the $\mathrm{CN}$ plays a major role in combustion. JB and MB made from vegetable oil have higher $\mathrm{CN}$ than diesel, thus leading to $\mathrm{HC}$ emissions. The average reduction of $\mathrm{HC}$ is $6.94 \%$ (J5), $11.58 \%$ (J10), $16.6 \%$ (J15), $25.86 \%$ (J20), 43.62\% (J40), 46.71\% (J60), $49 \%$ (J80), and 48.4\% (J100) lower than diesel. Similar decrease in trend was also observed in MB blends as 3.8\% (M5), 7.33\% (M10), 13.51\% (M15), 20.46\% (M20), 27.33\% (M40), 35.13\% (M60), 44.08\% (M80), and 49.03\% (M100). Thus, JB emits less UHC than MB. With an increase in the concentration of oxygen in blended fuels, more molecules get burnt and thus resulting in the completion of combustion process (Ashraful et al. 2014). Higher oxygen content results in complete efficient combustion, which in turn decreases the concentration of $\mathrm{HC}$ emissions concentration. Again, the delay in burning is due to decrease in $\mathrm{HC}$ as the biodiesel has greater $\mathrm{CN}$ than that of diesel.

\section{Conclusions}

The comparative study of $\mathrm{MB}$ and JB biodiesels and their respective blends were conducted to assess the engine performance, emissions and the characterization of biodiesels and their blends.

It was observed that BTE decreases with increasing concentration of JB and MB blends. The increasing trend of efficiency was also seen for diesel, JB and MB. The BTE for JB and MB blends were less than that of diesel due to their slow-burning rates, lower calorific values, poor volatility, and high viscosity. It was also observed that the average reduction of $\mathrm{HC}$ in MB was less than that in the case of JB as against diesel because of the higher oxygen content in JB. Similarly, the average reduction in CO was observed to be lower in JB than MB as compared to diesel because of higher oxygen content in biodiesel resulting in complete combustion. All blends of JB exhibited less mean BSFC, EGT than MB. The average decrease in BTE was more in JB than MB. JB exhibited less $\mathrm{CO}$ and $\mathrm{UHC}$ emissions than MB.

Raman spectra showed $\mathrm{C}=0$ stretching between $1740-1750 \mathrm{~cm}^{-1}$ confirming biodiesel production. FTIR confirms the presence of ester carbonyl group at $1743 \mathrm{~cm}^{-1}$ in all blends of JB and MB. The linearity over the selected peak at $1745 \mathrm{~cm}^{-1}$ showed a high co-efficient $R^{2}=0.924$ in case of JB and its blends and $R^{2}=$ 0.918 in case of MB.

The UV-vis linearity for both JB and MB showed a high coefficient of determination $\left(R^{2}=0.9064\right.$ and 0.9635); again, ${ }^{1} \mathrm{HNMR}$ and ${ }^{13} \mathrm{C}$ NMR spectra exhibited signal at $3.6 \mathrm{ppm}$ and $51.2 \mathrm{ppm}$ due to the methyl ester moiety and methoxy carbon respectively confirming production of biodiesel. Thus, the characterization techniques showed the quantification of different JB and MB blends of biodiesel.

On the basis of the analysis of performance and emission and characterization results analysis it is concluded that JB was better fuel than MB. 


\section{Declarations}

Ethics approval and consent to participate: Not Applicable

Consent for publication: Not Applicable

Availability of data \& material: Biodiesels were produced, and experiments were performed in IC Engine lab and Central Institute of Technology at Birla Institute Technology, Mesra. Data and materials comply with field standard. All data generated or analysed during this study are included in this article (and supplementary sheet).

Competing interests: Authors declare that they have no competing interests.

Funding: Not Applicable

Author's Contribution: Conceptualization, material preparation, methodology analysis was performed by [Rajeshwari Chatterjee]. The first draft of the manuscript was written by [Rajeshwari Chatterjee]. Reviewing, editing, technical checking was done by [Sanat Kumar Mukherjee, Rajeshwari Chatterjee]. All authors commented on previous versions of the manuscript [Rajeshwari Chatterjee, Sanat Kumar Mukherjee, Biswajit Paul, Somnath Chattopadhyaya]. All authors read and approved the final manuscript.

Acknowledgement: The authors are thankful to the Central Instrumentation Facility, Birla Institute of Technology, Mesra, Ranchi, India for conducting the experiments.

\section{References}

1. Acharya N, Nanda P, Panda S, Acharya S (2017) Analysis of properties and estimation of optimum blending ratio of blended mahua biodiesel. Engineering Science and Technology an International Journal 20: 511-517

2. Acharya N, Nanda P, Panda S, Acharya S (2019) A comparative study of stability characteristics of mahua and jatropha biodiesel and their blends. Journal of King Saud University-Engineering Sciences 31: 184-190

3. Anderson L A, Annaliese K F (2012) Real-time monitoring of transesterification by $1 \mathrm{H}$ NMR spectroscopy: catalyst comparison and improved calculation for biodiesel conversion. Energy \& Fuel. 26: 6404-6410

4. Ashraful A, Masjuki H, Kalam M A, Rashedul H, Sajjad H, Abedin M J (2014) Influence of anticorrosion additive on the performance, emission and engine component wear characteristics of an IDI diesel engine fueled with palm biodiesel. Energy Conversion and Management. 87:48-57

5. Bacha K, Ben-Amara A, Vannier A, Alves-Fortunato M, Nardin M (2015) Oxidation stability of diesel/biodiesel fuels measured by a PetroOxy device and characterization of oxidation products. Energy Fuels 29:4345-4355 
6. Berman P, Meiri N, Linder C, Wiesman Z (2016). $1 \mathrm{H}$ low field nuclear magnetic resonance relaxometry for probing biodiesel autoxidation. Fuel 177: 315-325.

7. Bondioli P, Gasparoli A, Della Bella,L, Tagliabue S, Toso G (2003) Biodiesel stability under commercial storage conditions over one year. European Journal Lipid Science Technology 105: 735-741

8. Bradley M (2007) Bio-diesel (FAME) Analysis by FT-IR. Available http://www.thermo.com/eThermo/CMA/PDFs/Articles/articlesFile_2448.pdf.

9. Chatterjee R, Mukherjee S K (2018) Spectroscopic Analysis and Performance Studies of Jatropha Extracted Bio-diesel. Waste and Biomass Valorization 9:1579-1585

10. Chatterjee R, Sharma V, Mukherjee S (2015) The environmental impacts and allocation methods used in LCA studies of vegetable oil-based bio-diesels: A review. Waste and Biomass Valorization 6(4) :579-603

11. Cheung CS, Zhu L, Huang Z (2009) Regulated and unregulated emissions from a diesel engine fueled with biodiesel and biodiesel blended with methanol. Atoms Environ 43:4865-4872

12. Chuck CJ, Bannister CD, Hawley JG, Davidso M G (2010) Spectroscopic sensor techniques applicable to real-time bio-diesel determination. Fuel. 89:457-461

13. Datta A, Mandal B K (2018) Numerical prediction of the performance, combustion and emission characteristics of a $\mathrm{Cl}$ engine using different biodiesels. Clean Technologies and Environmental Policy 20: 1773-1790

14. Devan PK, Mahalakshmi NV (2009) A study of the performance, emission and combustion characteristics of compression ignition engine using methyl ester of paradise oil eucalyptus oil blends. Applied Energy $86: 675-678$

15. Faraguna F, Marko R, Ante J (2019) Test method for determination of different biodiesels (fatty acid alkyl esters) content in diesel fuel using FTIR-ATR. Renewable energy 133: 1231-1235

16. Ganesan S, Mahalingam S, Shyam Daniel Raj R A, Rajesh S (2020) Effects of Nano additives on performance and emission characteristics of Mentha longifolia biodiesel. International Journal of Ambient Energy 41:322-325

17. Ghesti G F, de Macedo J L, Braga V S, de Souza, A T, Parente V C, Figuerêdo E S.... Dias S C (2006) Application of raman spectroscopy to monitor and quantify ethyl esters in soybean oil transesterification. Journal of the American Oil Chemists' Society 83:597-601

18. Ghesti GF, de Macedo J L, Resck I S, Dias J A, Dias S C L (2007) FT-Raman spectroscopy quantification of biodiesel in a progressive soybean oil transesterification reaction and its correlation with 1H NMR spectroscopy methods. Energy Fuels 21: 2475-2480

19. Jain S, Sharma M P (2011) Oxidation stability of blends of Jatropha biodiesel with diesel. Fuel 90: 3014-3020

20. Joshi R M, Pegg J (2007) Flow properties of biodiesel fuel blends at low temperatures. Fuel 86:143151 
21. Kalam MA, Masjuki HH, Jayed MH, Liaquat AM (2011) Emission and performance characteristics of an indirect ignition diesel engine fueled with waste cooking oil. Energy. 36 :397-402

22. Kannan G R (2019) Effect of Catalyzed Particulate Filter and Metal-Based Additive-Added Biodiesel on Engine Emissions. Environmental Engineering Science 36: 589-603.

23. Karavalakis G, Stournas S (2010) Impact of antioxidant additives on the oxidation stability of diesel/biodiesel blends.G. Karavalakis, S. Stournas, Energy Fuels 24 :3682-3686

24. Knothe G (2001) Determining the blend level of mixtures of biodiesel with conventional diesel fuel by fiber-optic near-infrared spectroscopy and ${ }^{1} \mathrm{H}$ Nuclear Magnetic Resonance spectroscopy. Journal of the American Oil Chemists' Society 78:1025-1028

25. Knothe G, Sharp C A, Ryan T W (2006) Exhaust emissions of biodiesel, petrodiesel, neat methyl esters, and alkanes in a new technology engine. Energy \& Fuels 20: 403-408

26. Miranda A M, Castilho-Almeida E W, Ferreira E H M, Moreira G F, Achete C A, Armond R A, Jorio A (2014) Line shape analysis of the Raman spectra from pure and mixed biofuels esters compounds. Fuel 115, 118-125

27. Monteiro M R, Ambrozin A R P, Lião L M, Ferreira A G (2009) Determination of bio-diesel blend level in different diesel samples by ${ }^{1}$ H NMR. Fuel 88: 691-696.

28. Pantoja S S. da Conceição LRV, da Costa CE, Zamian JR, da Rocha Filho G. (2013) Oxidative stability of biodiesels produced from vegetable oils having different degrees of unsaturation. Energy Conversion Management 74: 293-298

29. Pinzi S, Rounce P, Herreros J M, Tsolakis A, Dorado M P (2013) The effect of biodiesel fatty acid composition on combustion and diesel engine exhaust emissions. Fuel 104: 170-182

30. Raheman H, Ghadge S V (2007) Performance of compression ignition engine with mahua (Madhuca indica) biodiesel. Fuel 86: 2568-2573

31. Rashed M M, Kalam M. A, Masjuki H H, Mofijur M, Rasul M G, Zulkifli N W M (2016) Performance and emission characteristics of a diesel engine fueled with palm, jatropha, and moringa oil methyl ester. Industrial crops and products 79: 70-76

32. Satyarthi J K, D Srinivas, Paul R (2009) Estimation of free fatty acid content in oils, fats, and biodiesel by $1 \mathrm{H}$ NMR spectroscopy. Energy \& Fuels 23: 2273-2277

33. Schmidt K, Van Gerpen J The effect of biodiesel fuel composition on diesel combustion and emissions (No. 961086). SAE Technical Paper, No 961086 (1996)

34. Shah N S, Joshi A, Patel A P, Brahmkhatri V P (2013) Synthesis of Jatropha Oil based Biodiesel using Environmentally Friendly Catalyst and their Blending Studies with Diesel. Energy and Power 3:7-11

35. Shahabuddin M, Kalam M A, Masjuki H H, Bhuiya M M K, Mofijur M (2012) An experimental investigation into biodiesel stability by means of oxidation and property determination. Energy 44 : 616-622

36. Shimamoto GG, Tubino M (2016) Alternative methods to quantify biodiesel in standard dieselbiodiesel blends and samples adulterated with vegetable oil through UV-Visible spectroscopy. Fuel 
186: $199-203$

37. Tariq M, Ali S, Ahmad F, Ahma, M, Zafar M, Khalid N, Khan M A (2011). Identification, FT-IR, NMR ( ${ }^{1} H$ and ${ }^{13} \mathrm{C}$ ) and $\mathrm{GC} / \mathrm{MS}$ studies of fatty acid methyl esters in biodiesel from rocket seed oil. Fuel Processing Technology 92(3):336-341

38. Tat M E, Van Gerpen J H, Wang P S (2004) Fuel property effects on injection timing, ignition timing and oxides of nitrogen emissions from biodiesel-fuelled engines. American Society of Agricultural and Biological Engineers, 1

39. Vega-Lizama T, Díaz-Ballote L, Hernández-Mézquita E, May-Crespo F, Castro- Borges P, CastilloAtoche $A$, et al (2015) Thermogravimetric analysis as a rapid and simple method to determine the degradation degree of soy biodiesel. Fuel 156: 158-62

40. Zhou J, Xiong Y, Gong Y, Liu X (2017) Analysis of the oxidative degradation of biodiesel blends using FTIR, UV-Vis, TGA and TD-DES methods. Fuel 202: 23-28

\section{Figures}




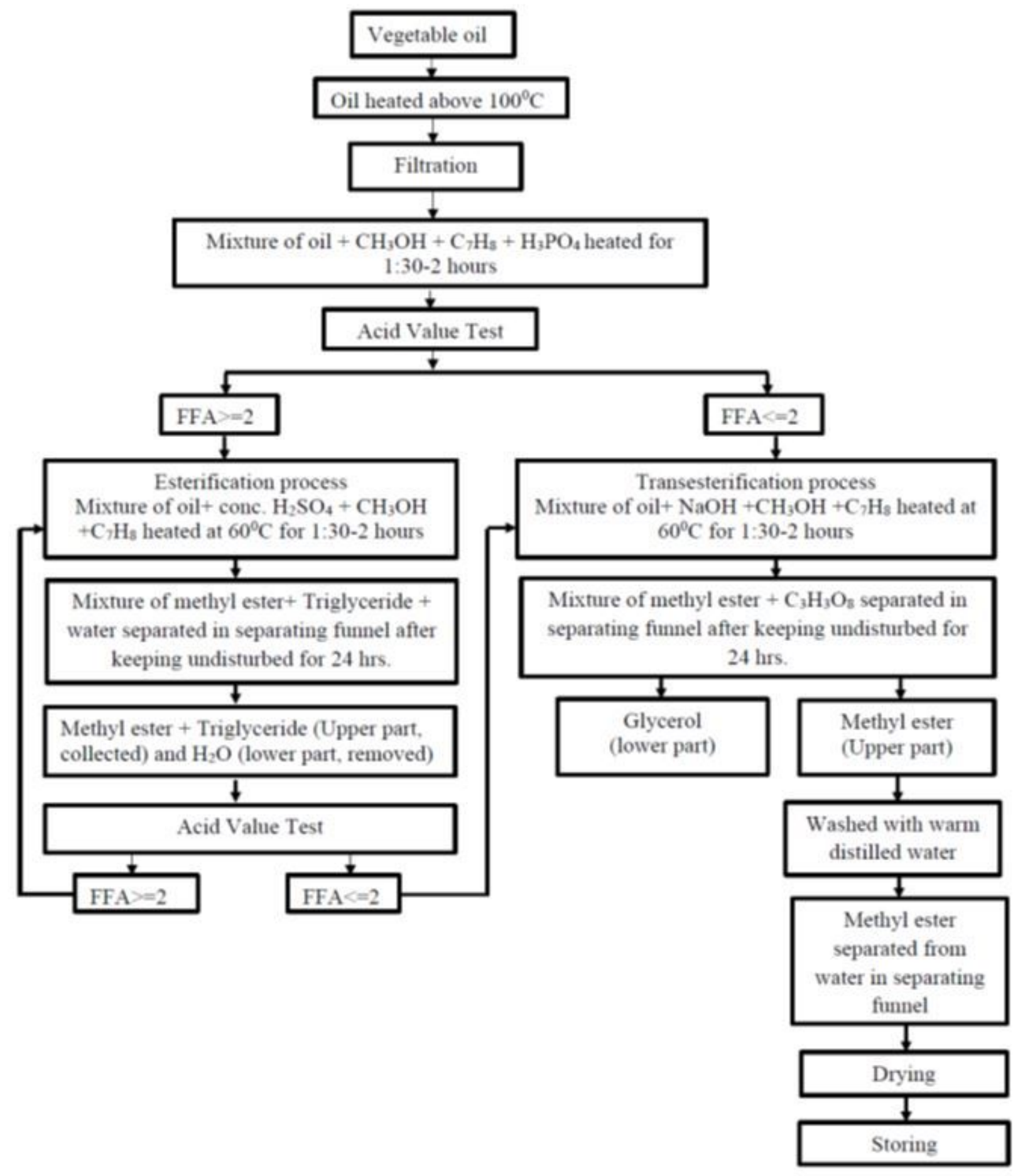

Figure 1

Schematic Diagram representing biodiesel production from Madhuca longifolia and Jatropha curcas. 


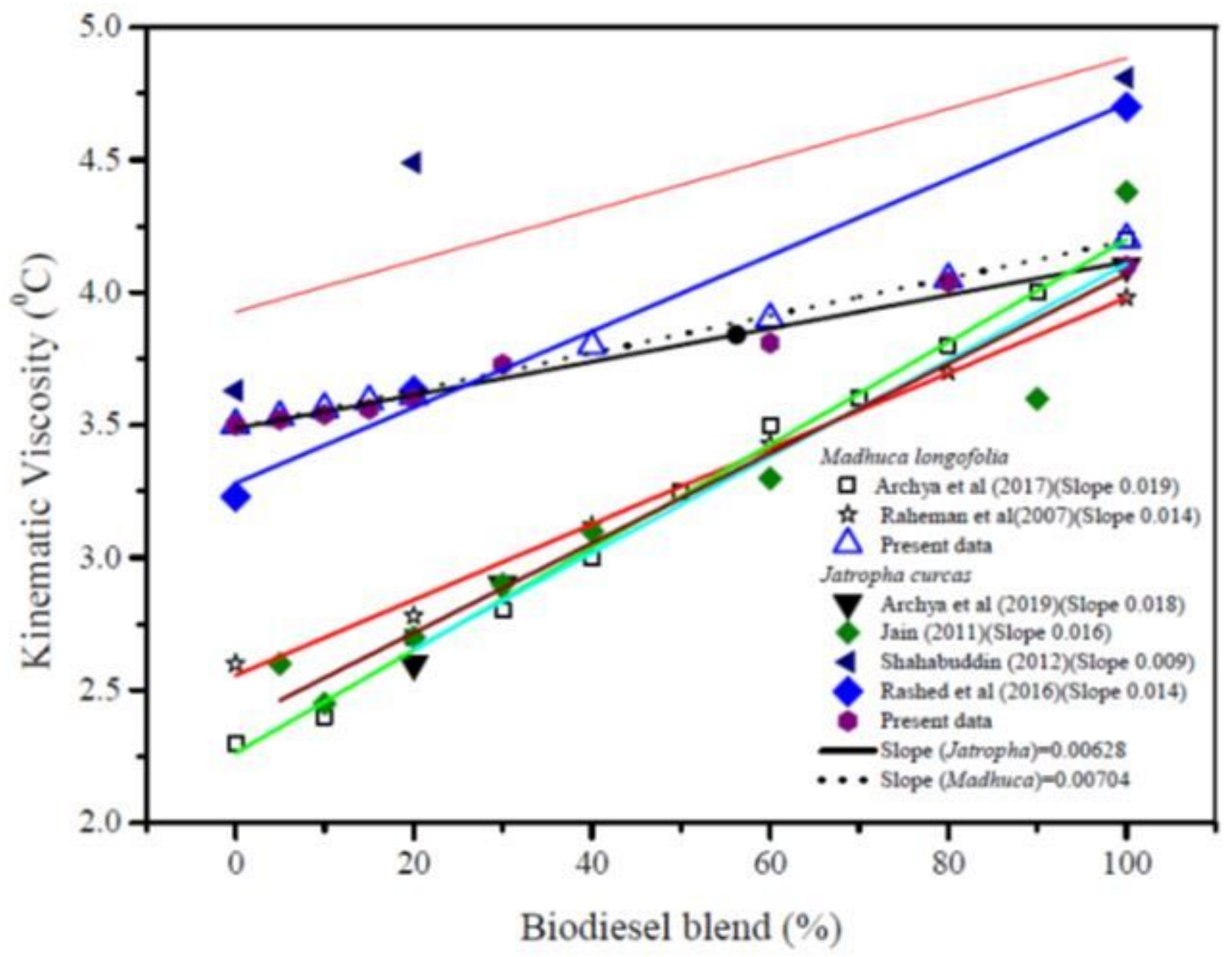

Figure 2

Kinematic viscosity of JB and MB. 


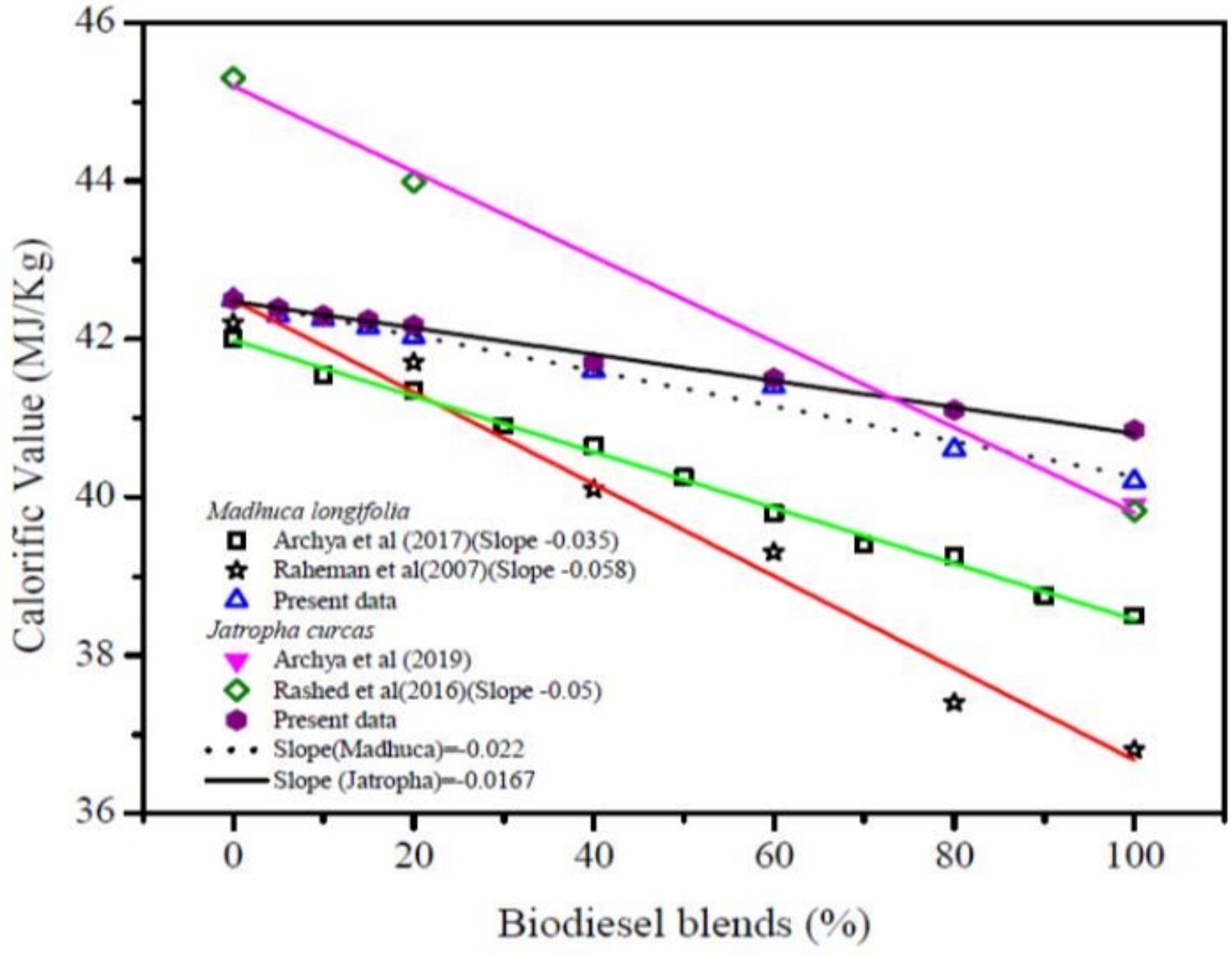

Figure 3

Calorific Value of JB and MB. 


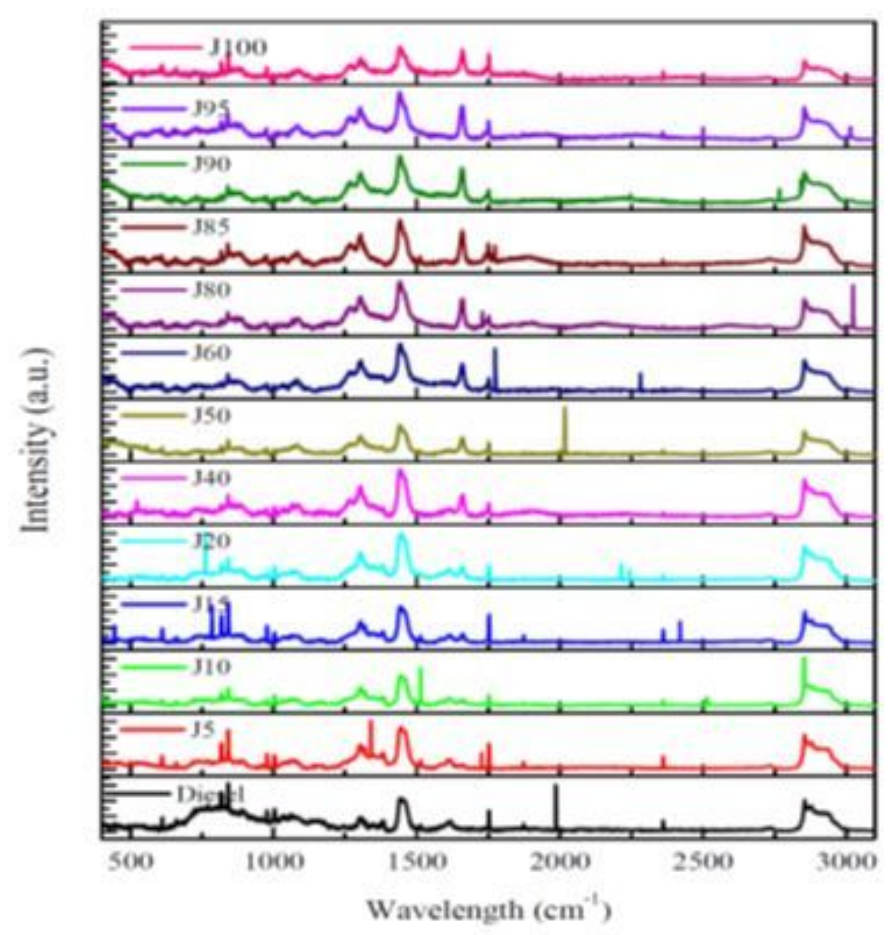

Fig. $4 a$

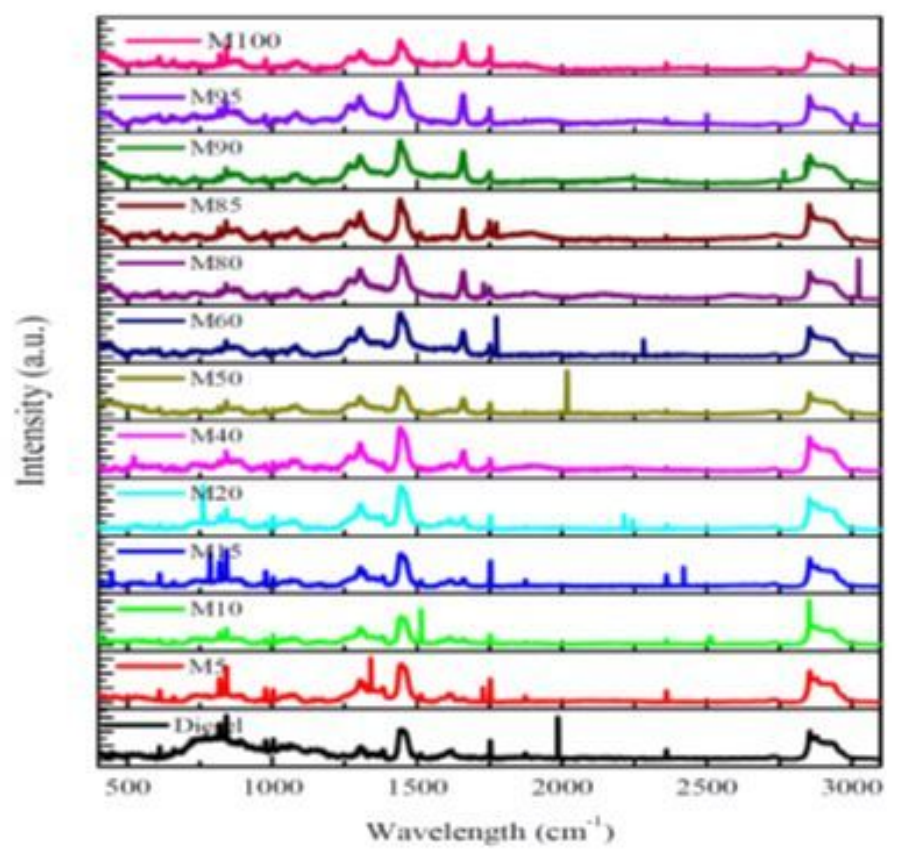

Fig. 4b

\section{Figure 4}

4a Raman spectra of diesel and different JB blends (J5-J20, J40, J50, and J80-J100). 4b Raman spectra of diesel and different MB blends (M5-M20, M40, M50, and M80-M100). 


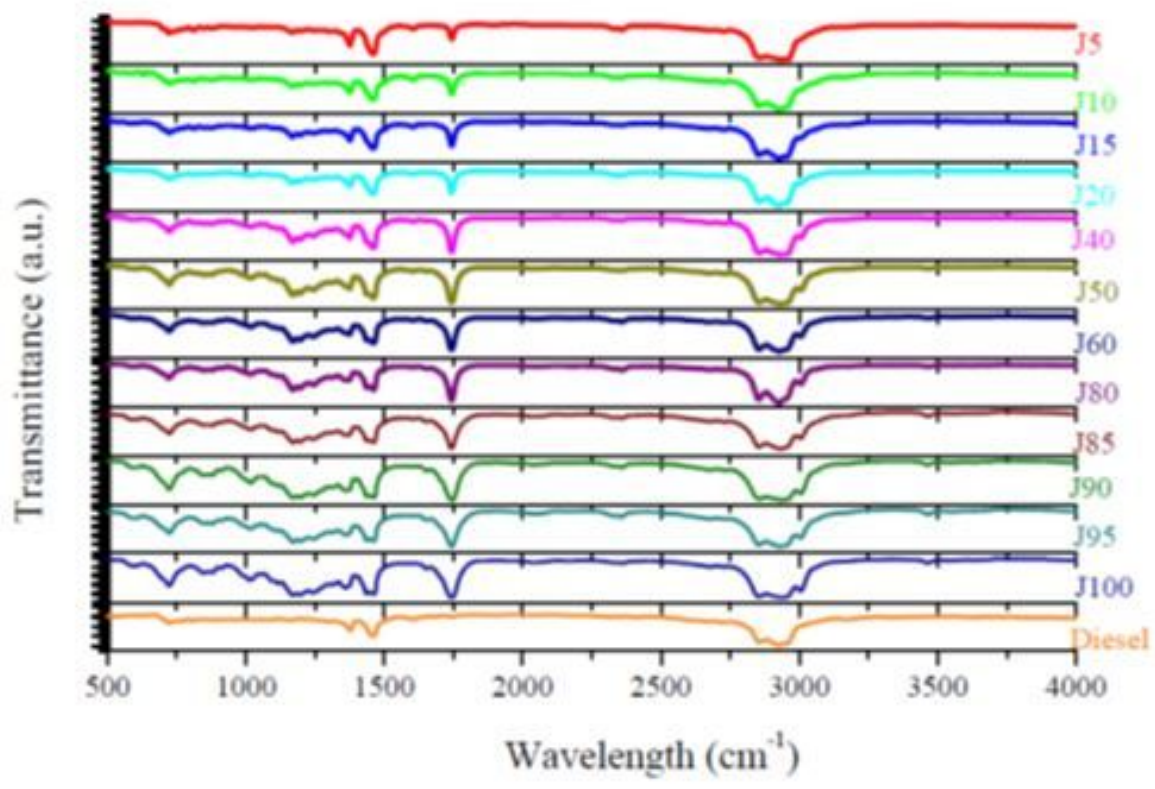

Fig. $5 a$

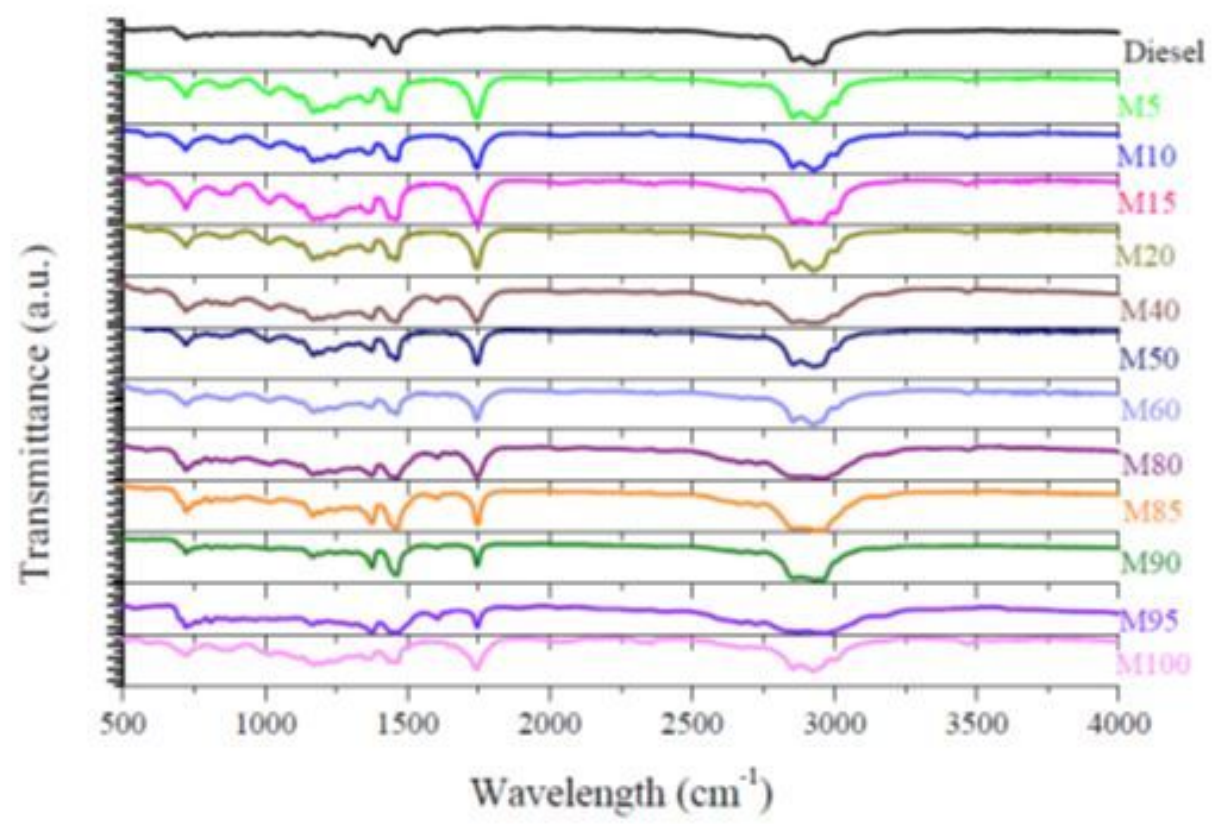

Fig. 5b

\section{Figure 5}

5a FTIR of diesel and different JB blends (J5-J20, J40, J50, and J80-100). 5b FTIR of diesel and different MB blends (M5-M20, M40, M50, and M80-M100). 


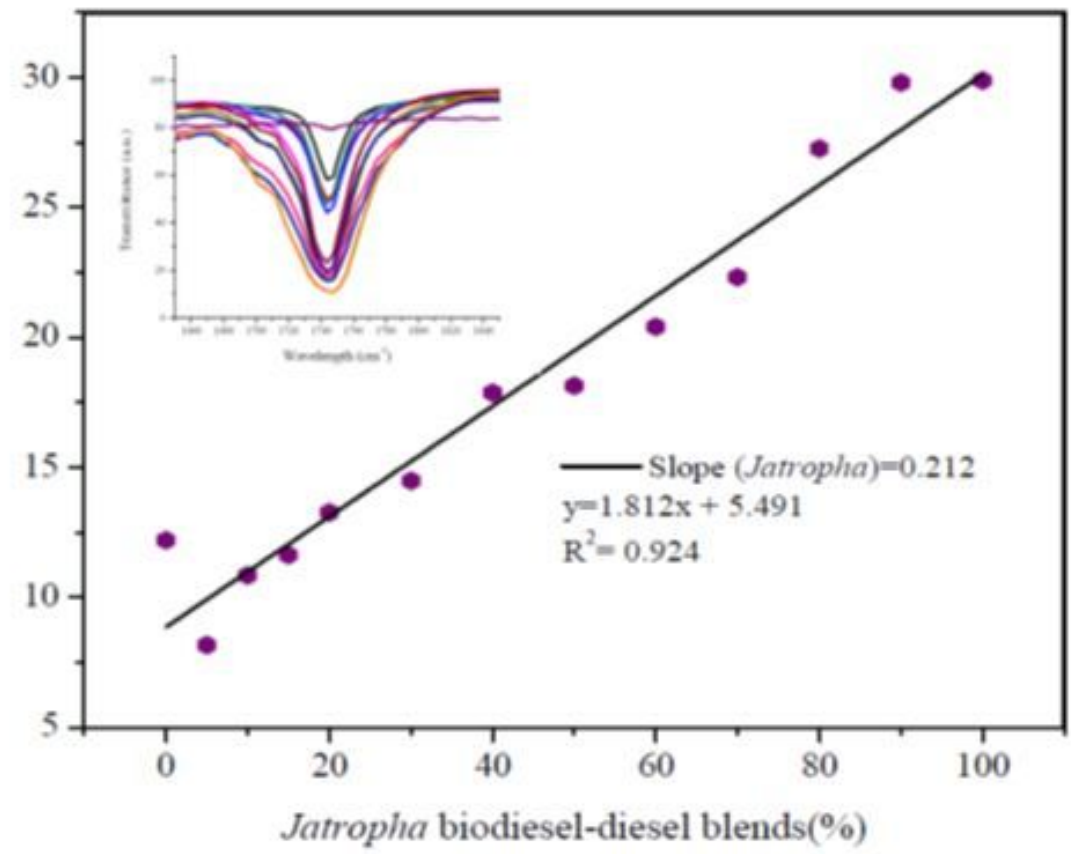

Fig. 6a

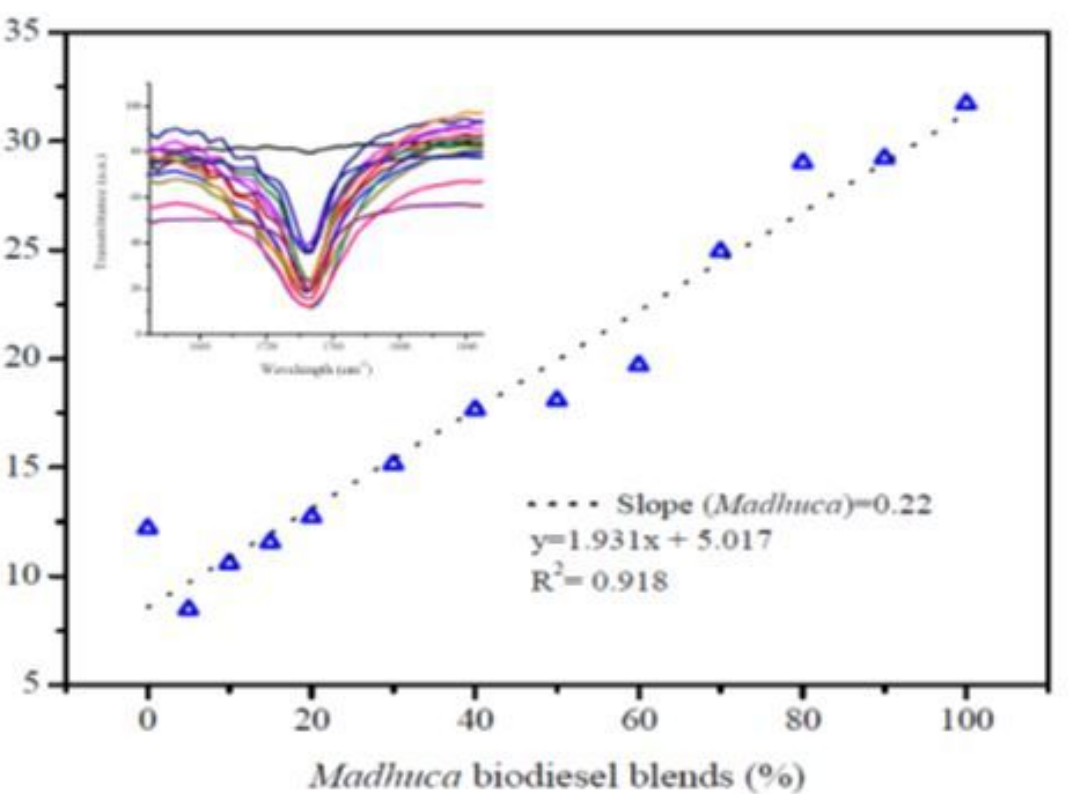

Fig. 6b

Figure 6

6a Transmittance of diesel \& blended percentages of JB. 6b Transmittance of diesel \& blended percentages of MB. 


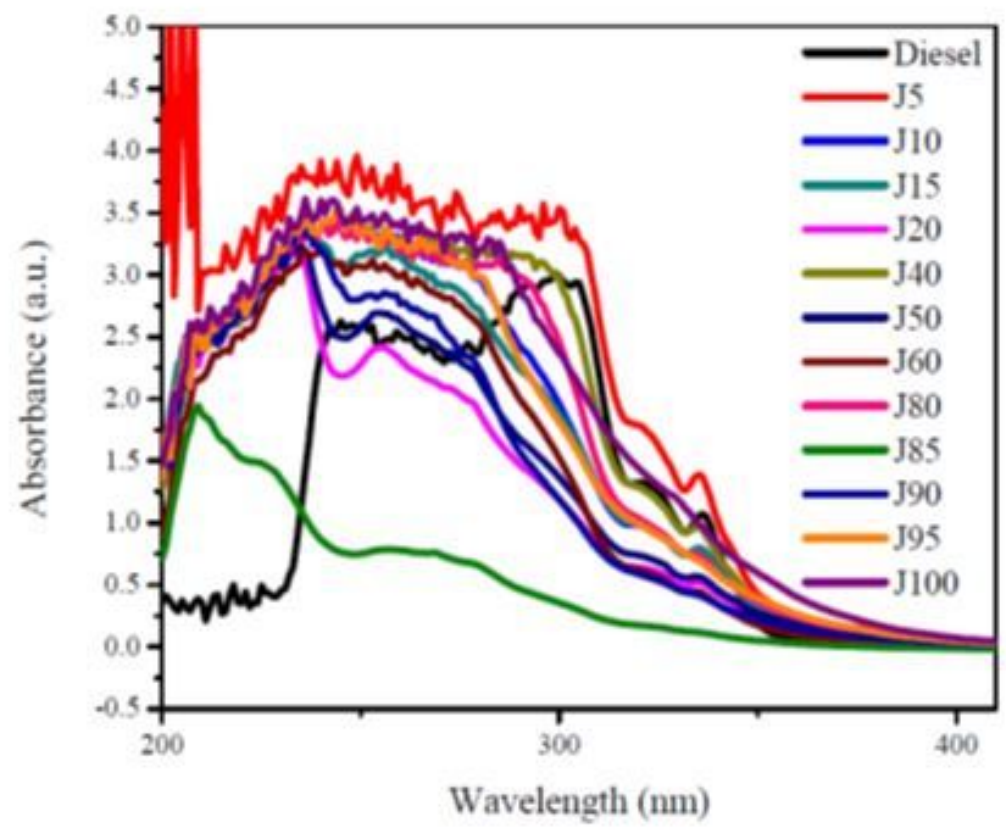

Fig. 7a

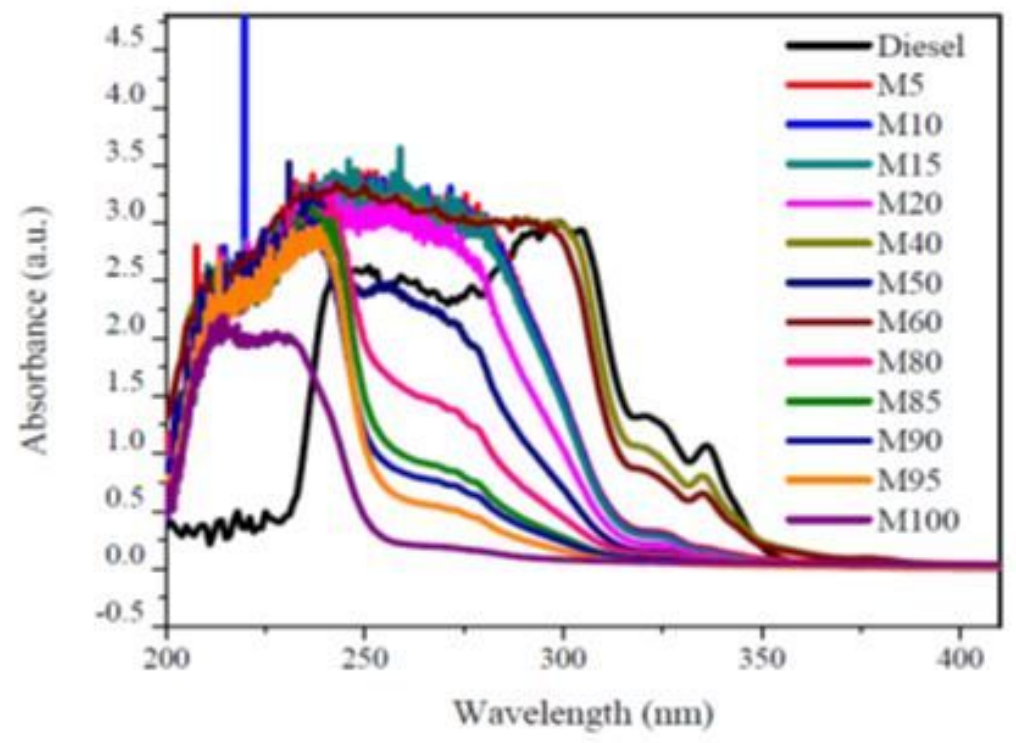

Fig. $7 b$

Figure 7

7a UV-Vis of diesel and different JB blends (J5-J20, J40, J50, and J80-100). 7b UV-Vis of diesel and different MB blends (M5-M20, M40, M50, and M80-M100). 


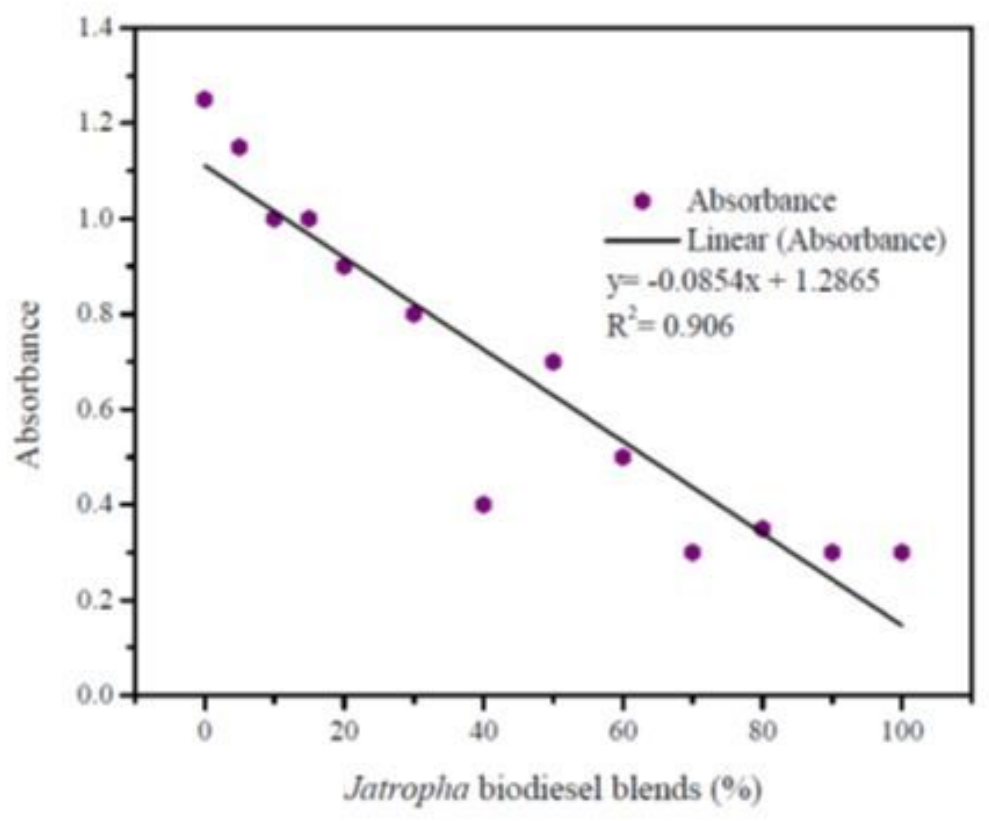

Fig. $8 a$

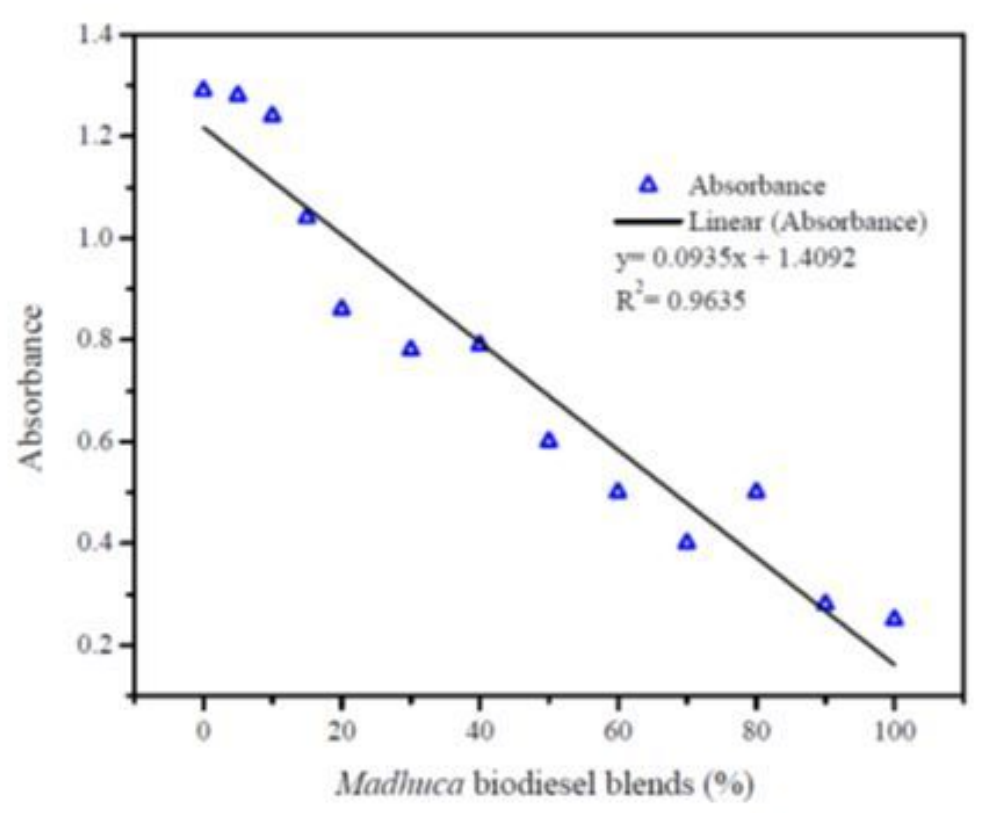

Fig. $8 \mathrm{~b}$

\section{Figure 8}

8a Absorbance of diesel and blended percentages of JB. 8b Absorbance of diesel and blended percentages of MB. 


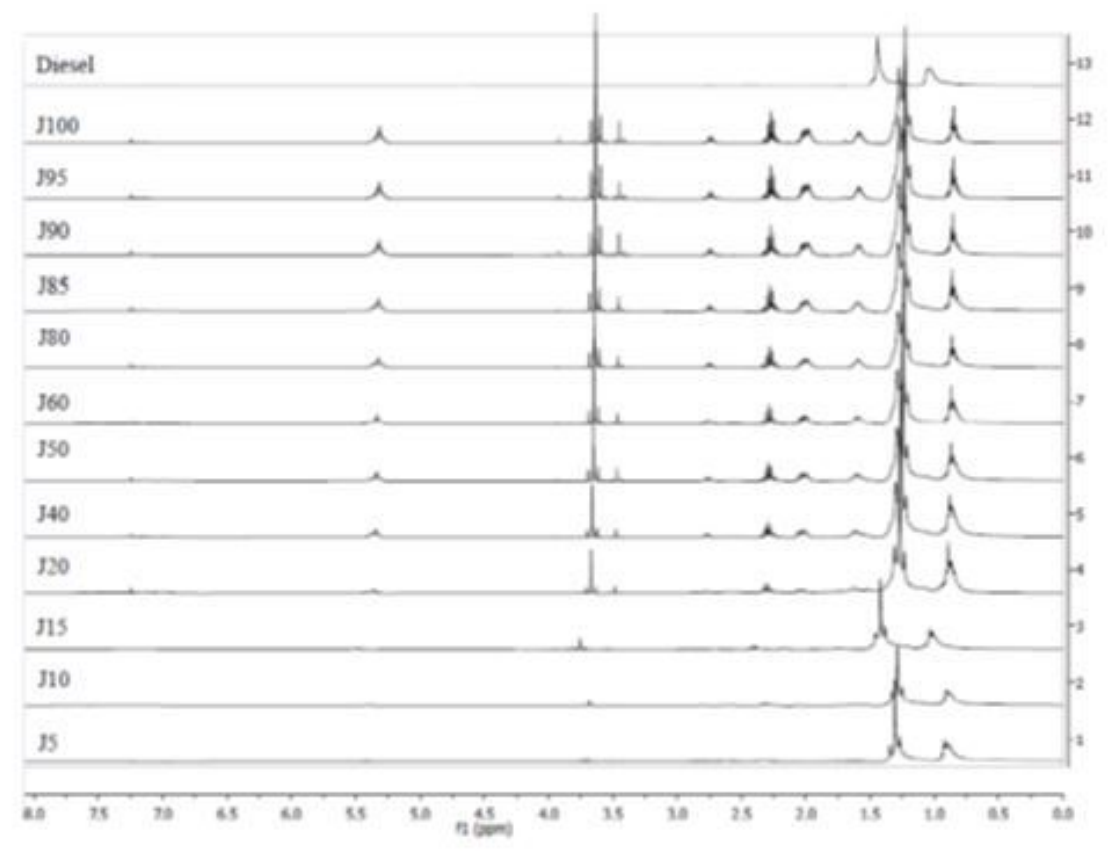

Fig. 9a

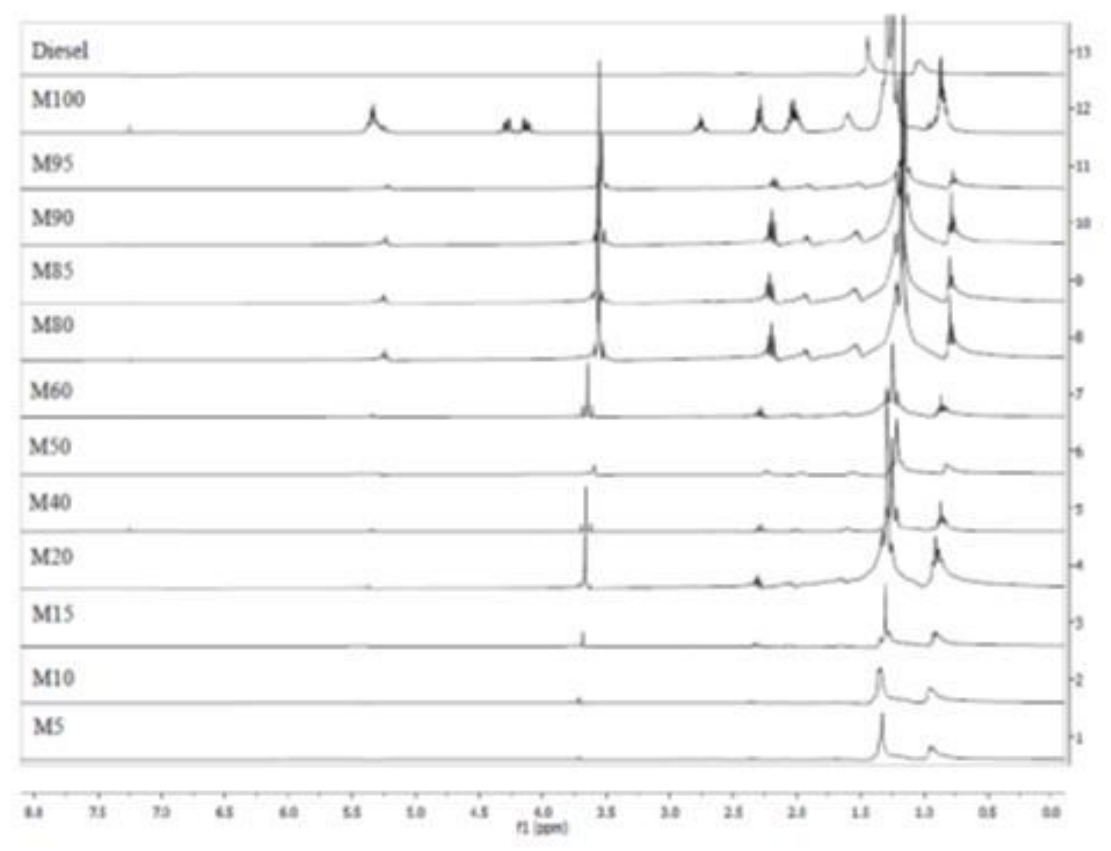

Fig. 9b

\section{Figure 9}

9a 1H NMR spectra of blending samples of JB with diesel ((J5-J20, J40, J50, J80-100). 9b 1H NMR spectra of blending samples of MB with diesel (M5 to M100). 


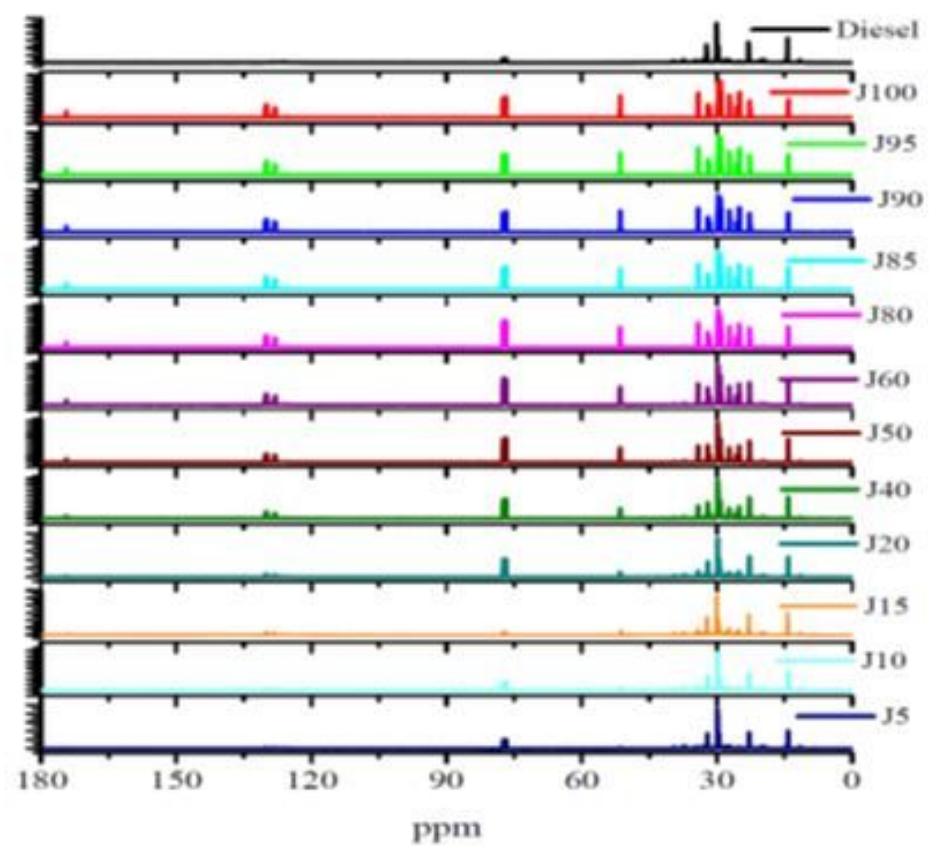

Fig. 10a

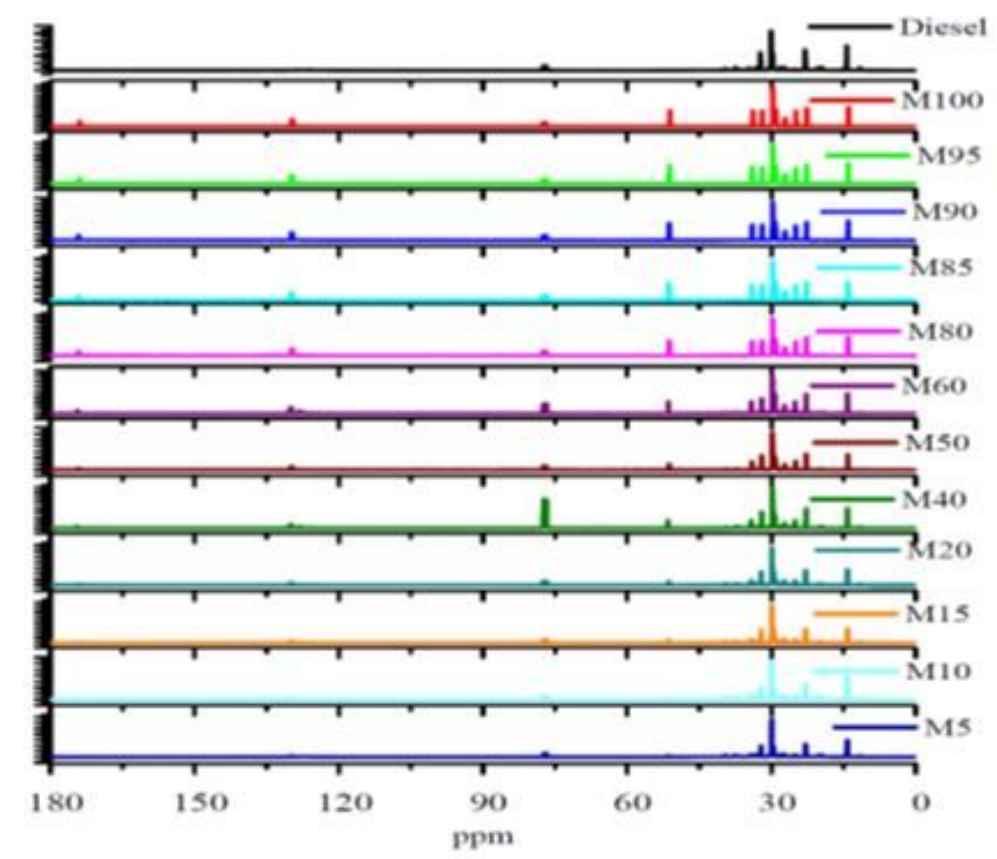

Fig. 10b

Figure 10

10a 13CNMR spectra of blending samples of JB with diesel ((J5-J20, J40, J50, J80-100). 10b 13CNMR spectra of blending samples of JB with diesel ((J5-J20, J40, J50, J80-100). 


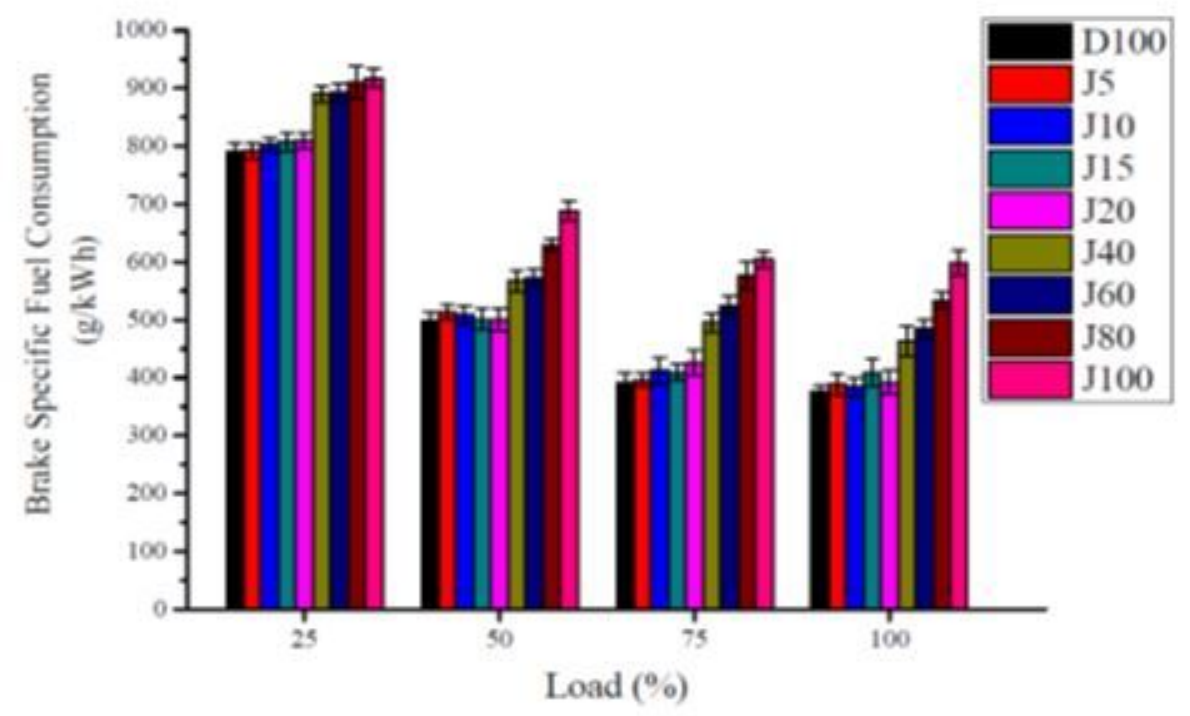

Fig. 11a

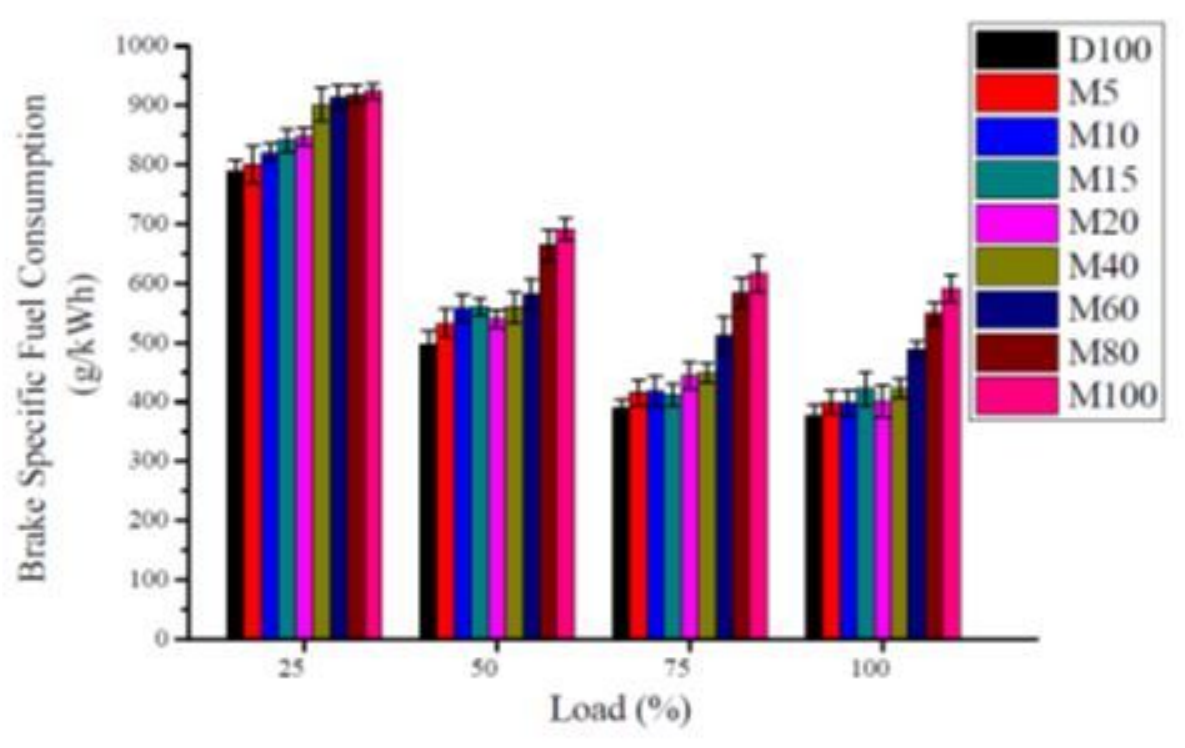

Fig. 11b

\section{Figure 11}

11a Variations of BSFC versus load (\%) for JB and its blends. 11b Variations of BSFC versus load (\%) for $\mathrm{MB}$ and its blends. 


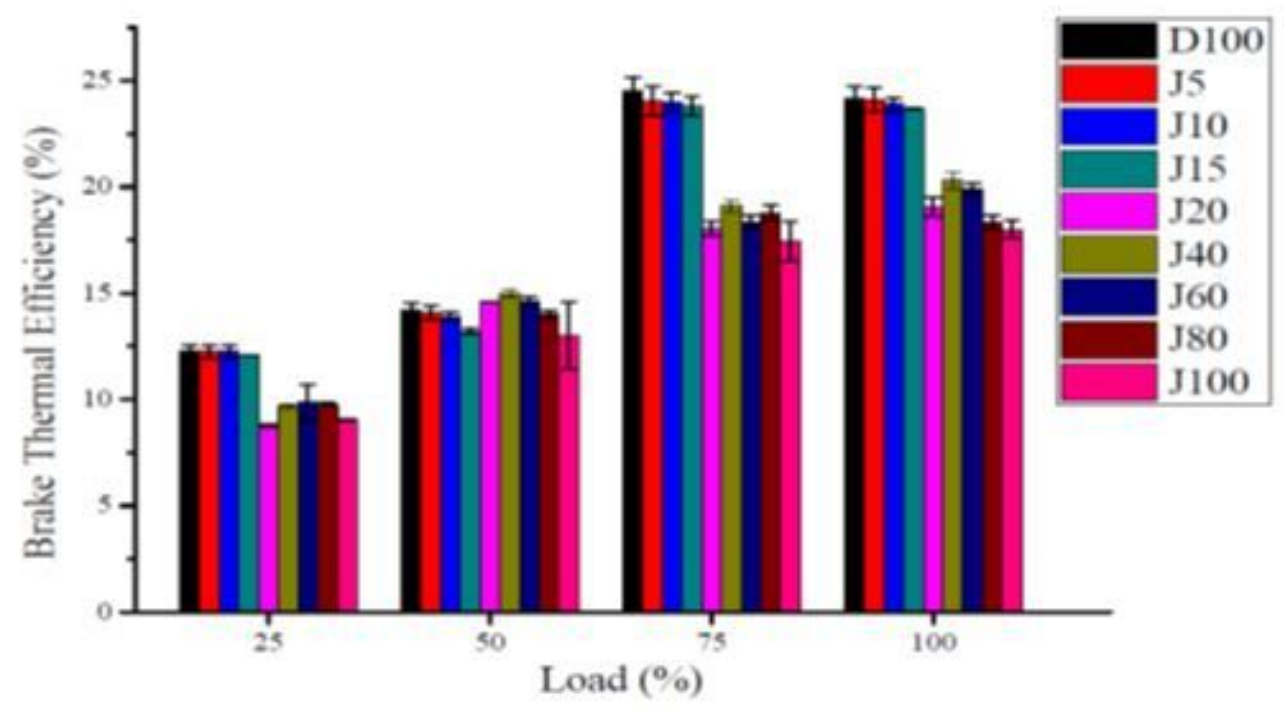

Fig. 12a

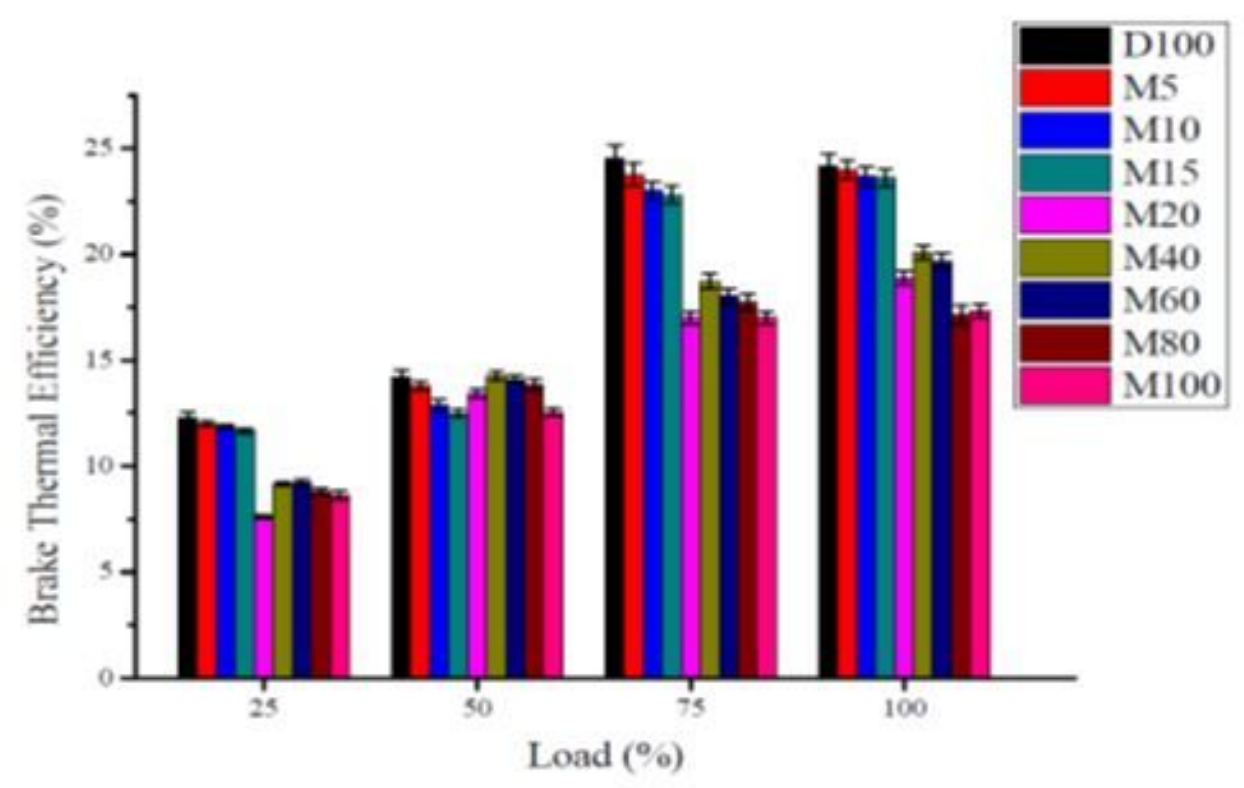

Fig. 12b

Figure 12

12a Variations of BTE versus load (\%) for JB and its blends. 12b Variations of BTE versus load (\%) for $\mathrm{MB}$ and its blends. 


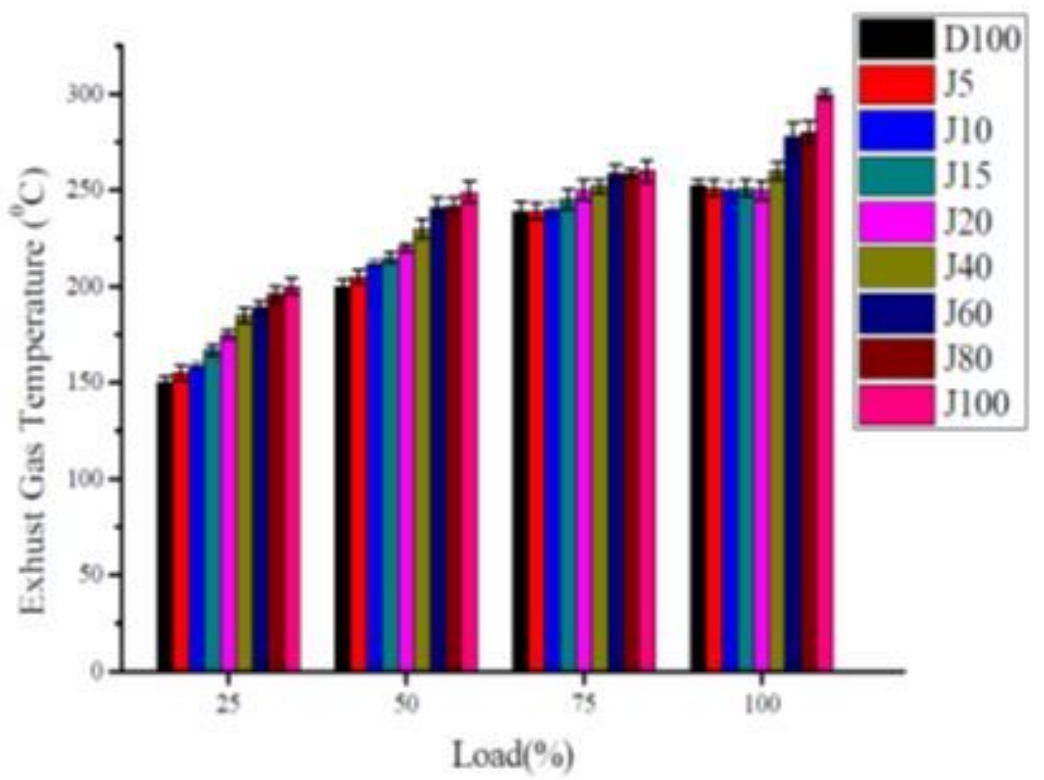

Fig. 13a

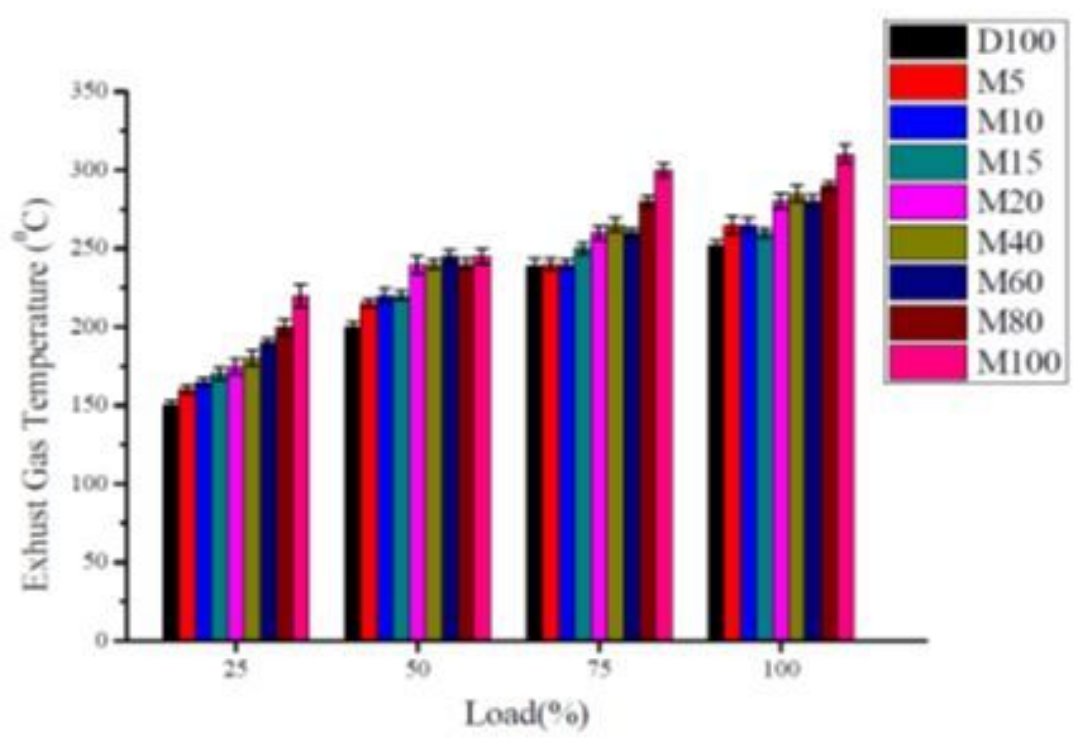

Fig. 13b

Figure 13

13a Variations of EGT versus load (\%) for JB and its blends. 13b Variations of EGT versus load (\%) for $\mathrm{MB}$ and its blends. 


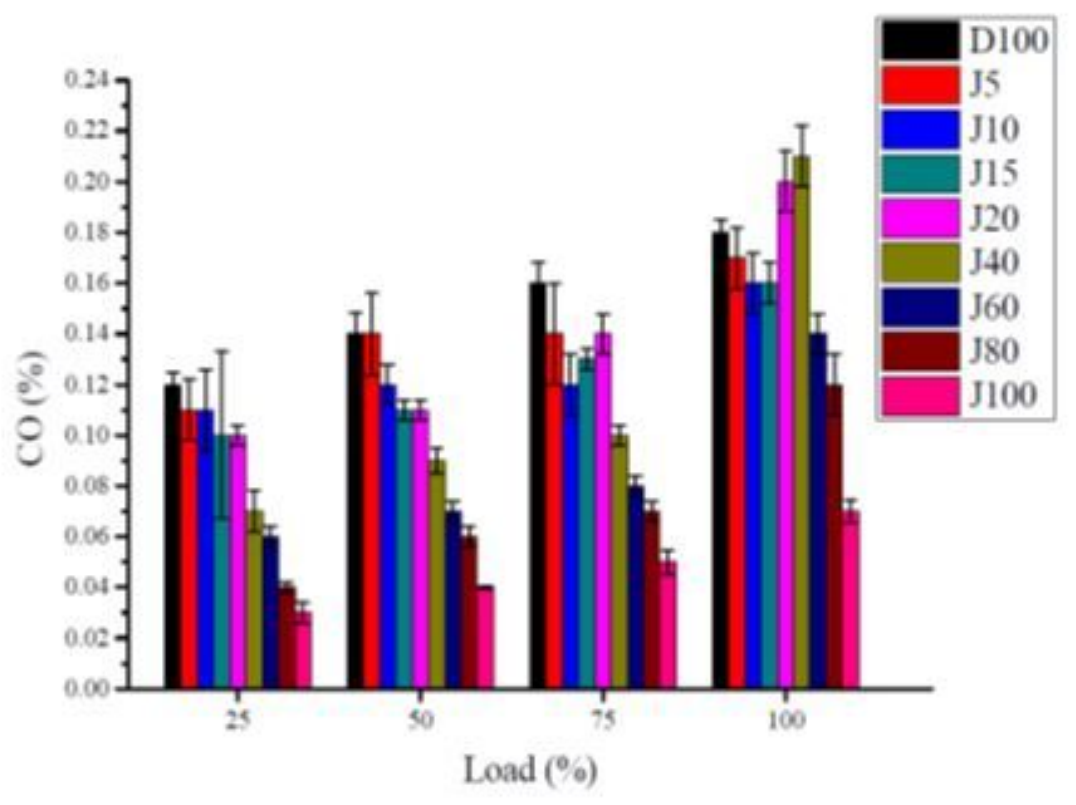

Fig. 14a

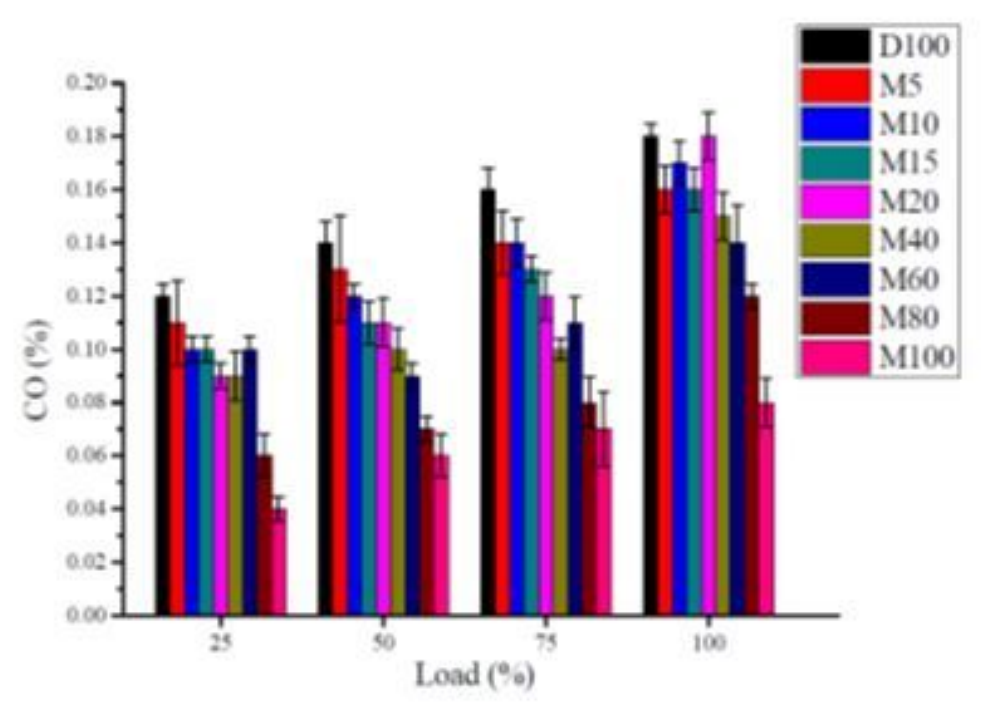

Fig. 14b

Figure 14

14a Variations of CO versus load (\%) for JB and its blends. 14b Variations of CO versus load (\%) for MB and its blends. 


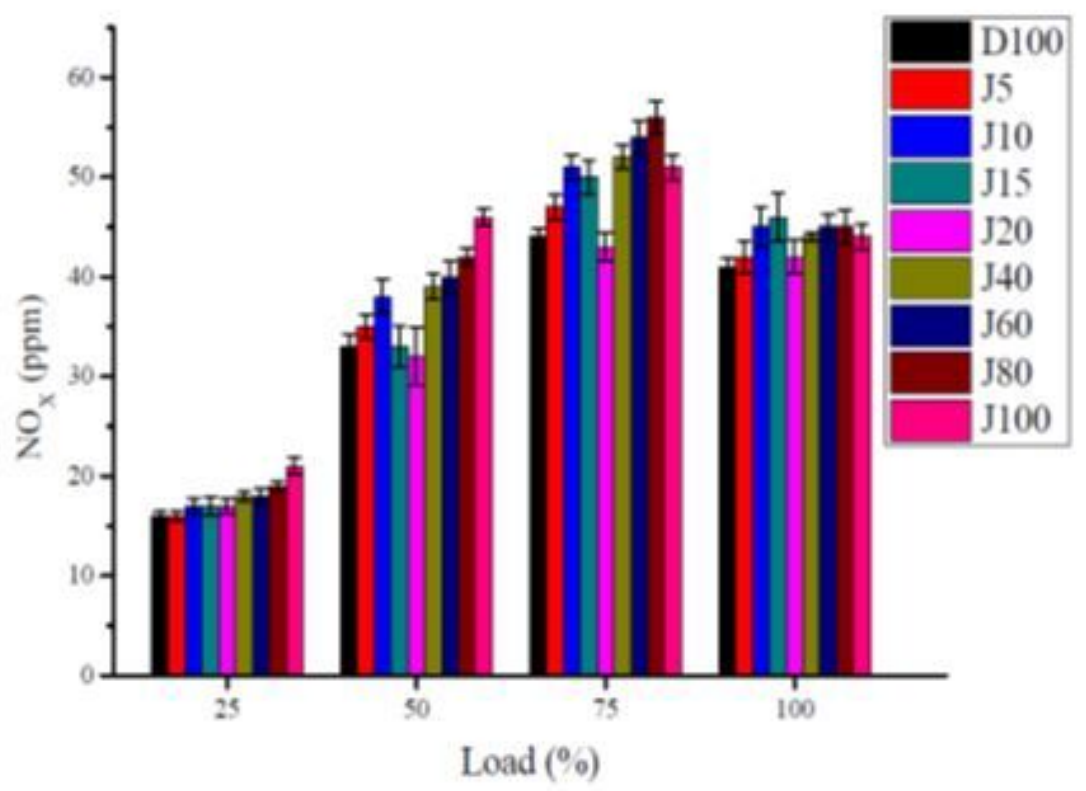

Fig. 15a

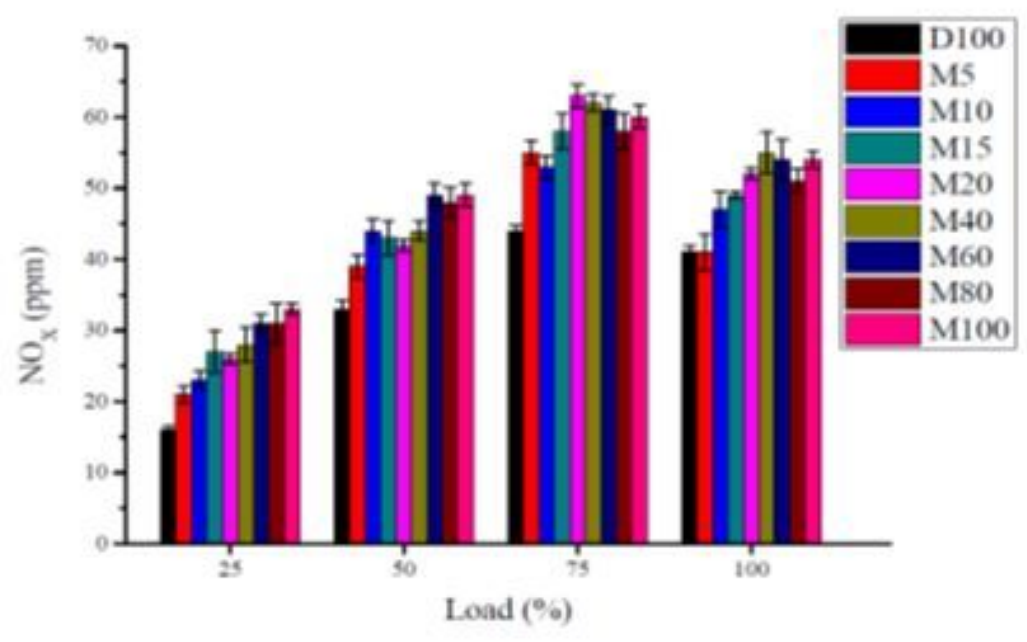

Fig. 15b

Figure 15

15a Variations of NOX versus load (\%) for JB and its blends. 15b Variations of NOX versus load (\%) for $\mathrm{MB}$ and its blends. 


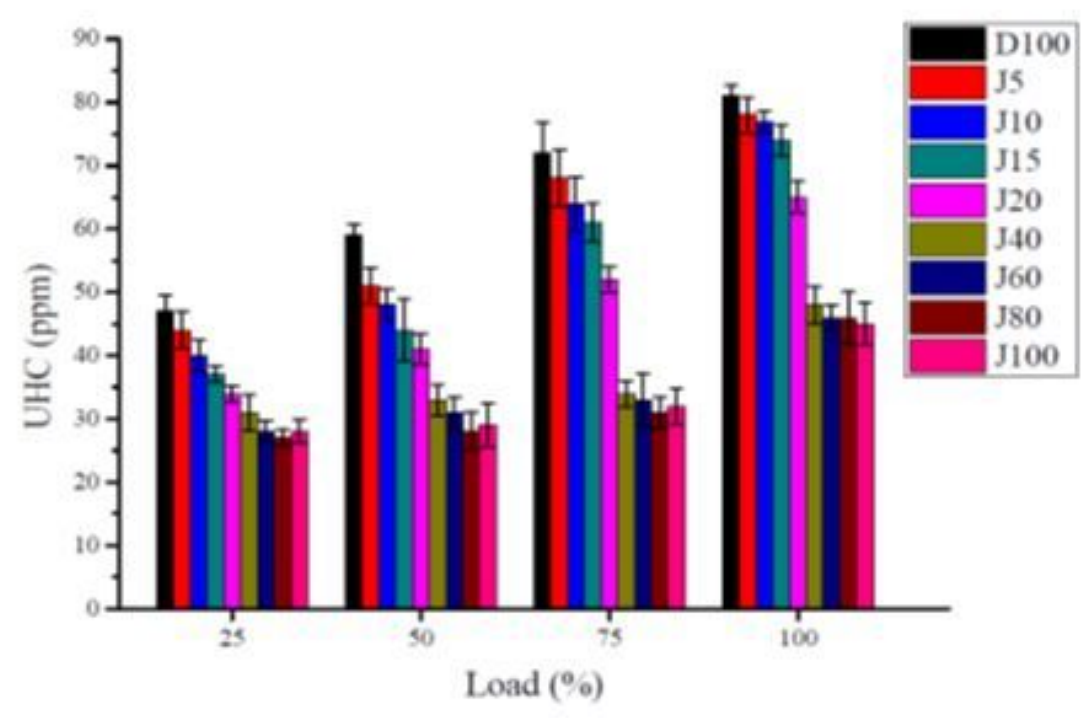

Fig. 16a

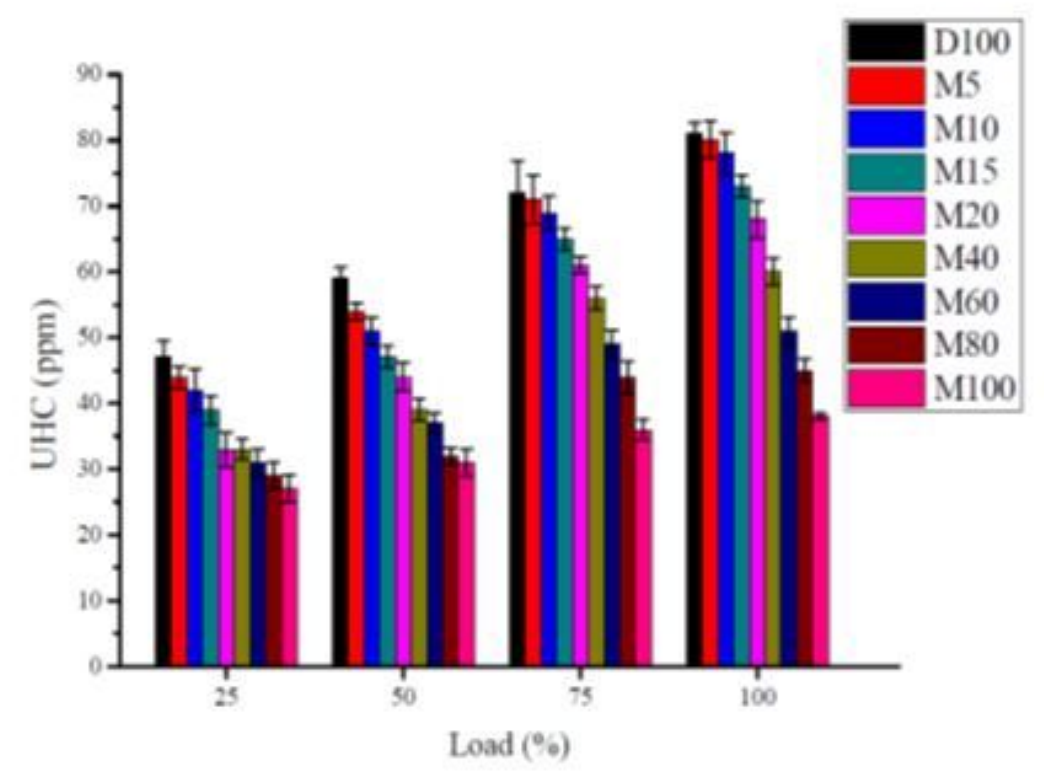

Fig. 16b

Figure 16

16a Variations of UHC versus load (\%) for JB and its blends. 16b Variations of UHC versus load (\%) for $\mathrm{MB}$ and its blends.

Supplementary Files 
This is a list of supplementary files associated with this preprint. Click to download.

- GraphicalAbstract.jpg

- SupplementarySheet.docx 